LIFE CYCLE COST STUDY FOR COATED CONDUCTOR MANUFACTURE BY ELECTRON BEAM AND PULSED LASER DEPOSITION SYSTEMS

Topical Report

Reporting Period Start Date: 06/01/1998 End Date: 04/01/1999

Author: Dr. James N. Chapman

Report Issue Date: 04/14/1999

DE-AC22-95PC95231--21

University of Tennessee space Institute

B. H. Goethert Parkway

Tullahoma, TN 37388-9700 


\title{
LIFE CYCLE COST STUDY FOR COATED CONDUCTOR MANUFACTURE BY ELECTRON BEAM AND PULSED LASER DEPOSITION SYSTEMS*
}

\author{
TOPICAL REPORT
}

James N. Chapman

The University of Tennessee Space Institute

Tullahoma, Tennessee 37388-9700

June 1998

(Revised April 1999)

*This work was performed under Contract No. DE-AC22-95PC95231 


\section{DISCLAIMER}

This report was prepared as an account of work sponsored by an agency of the United States Government. Neither the United States Government nor any agency thereof, nor any of their employees, makes any warranty, express or implied, or assumes any legal liability or responsibility for the accuracy, completeness, or usefulness of any information, apparatus, product, or process disclosed, or represents that its use would not fringe privately owned rights. Reference herein to any specific commercial product, process, or service by trade name, trademark, manufacturers, or otherwise does not necessarily constitute or imply its endorsement, recommendation, or favoring by the United States Government or any agency thereof. The views and opinions of authors expressed herein do not necessarily state or reflect those of the United States Government or any agency thereof. 
Table of Contents

1.0 Introduction

2.0 Description of the Production Facility and Assumptions Used .................................. 1

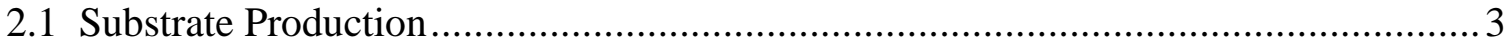

2.2 Application of YBCO Superconductor by Electron Beam Vaporization .................... 3

2.3 Application of the YBCO Superconductor by Pulsed Laser Deposition....................5

2.4 Passivation/Insulation Layer ........................................................................ 7

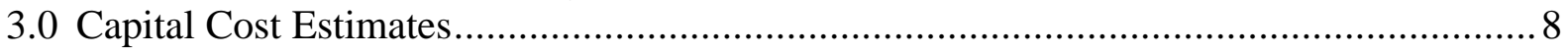

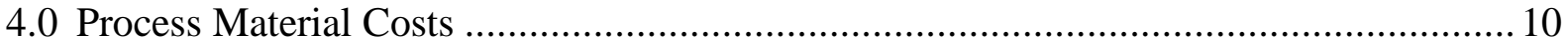

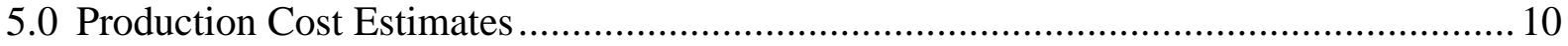

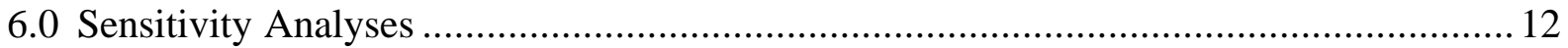

6.1 Cost Sensitivity to Deposition Rate ............................................................. 12

6.2 Cost Sensitivity to Capacity Factor .............................................................. 12

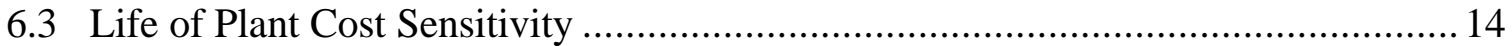

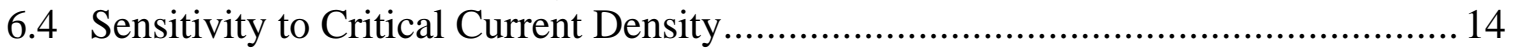

6.5 Cost Sensitivity to Material Utilization Rate ..................................................... 14

6.6 Sensitivity to Use of a Thicker Layer of Yttrium Stabilized Zirconia (YSZ).......... 16

6.7 Sensitivity to Thickness of Superconducting Layer ......................................... 16

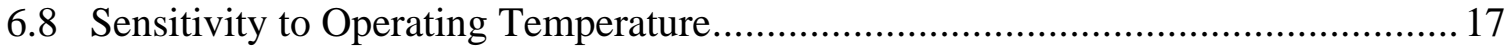

6.9 Cost Sensitivity to Laser Energy Target Removal Efficiency ............................... 17

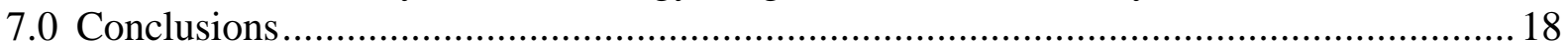

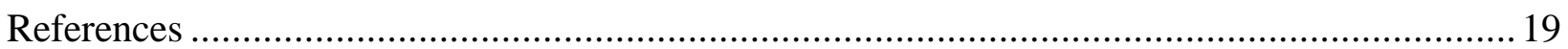




\section{List of Figures}

Figure 2.0-1 Assumed Conductor Configuration (not to scale) ........................................2

Figure 2.2-1 Concept for the Electron Beam Deposition Chamber ..................................... 4

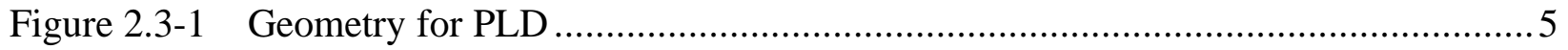

Figure 2.3-2 Pulsed Laser Deposition Concept ........................................................ 7

Figure 6.1-1 Cost Sensitivity to Deposition Rate .......................................................... 13

Figure $6.2-1$ Cost Sensitivity to Capacity Factor ........................................................... 13

Figure 6.3-1 Cost Sensitivity to Plant Lifetime ........................................................ 14

Figure 6.4-1 Cost Sensitivity to Critical Current Density ........................................... 15

Figure 6.5-1 Cost Sensitivity to Material Utilization Fraction......................................... 15 


\section{List of Tables}

Table 2-1

Table 2.2-1

Table 3.0-1

Table 3.0-2

Table 4.0-1

Table 5.0-1

Table 5.0-2

Table 5.0-3

Table 6.6-1

Table 6.7-1

Table 6.8-1

Table 6.9-1
Assumption Used in the Study

page

Ideal Deposition Power Required

Capital Cost Estimates for the Plant

Process Control System Cost Estimates

Consumable Cost for Assumed Production

Annual Capital Charge Components

Staffing Basis for the Plants Under Consideration

Production Cost Summary

Cost Impact of Requiring a 2,000 ^̊ Thick YSZ Buffer Layer

Effect of Increased Superconductor Layer Thickness

Wire Manufacturing Cost Versus Operating Temperature

Cost Sensitivity to Laser Target Removal Efficiency.

\section{2}

\section{4}




\subsection{Introduction}

Recent results from small laboratory samples have shown performance of high temperature superconductors made by epitaxial deposition in thin films to be approaching the performance needed for commercial production and application. ${ }^{1,2}$ One of the biggest hurdles to widespread application of these wires is developing a manufacturing process that will produce them in long lengths and at prices competitive to copper for applications such as motors, generators, transformers and power transmission cables.

Most of the good quality laboratory samples have been produced by Pulsed Laser Deposition (PLD) of the superconductor onto a textured substrate which has been epitaxially coated with buffer layers to provide chemical isolation and to improve the lattice match. In the PLD process for application of the YBCO layer, an excimer laser is pulsed onto a target of YBCO in a vacuum chamber which produces a beam of particulate on the sample to be coated, which is heated to a temperature favorable for formation of the desired YBCO compound. ${ }^{3}$ The laser provides a pulse of approximately 0.5 Joule on a small spot that expels the YBCO material for the pulse duration. These excimer lasers are typically limited to about 200 watts of average power and cost about $\$ 2,800$ per watt of power delivered to the target. ${ }^{4,5}$

There are several alternative processes for deposition of materials onto the substrate. UTSI has studied and compared the most commonly known processes including: PLD, electron beam, sputtering, flash evaporation, molecular beam epitaxy, electrophoresis, chemical vapor deposition, sol-gel, metal organic decomposition, electrode position and aerosol/spray pyrolysis. ${ }^{6}$ The electron beam process is being studied by at least one company, 3M, for possible utilization in a production facility. ${ }^{7}$ Also, Dr. Robert Hammond at Stanford University has studied this process. ${ }^{8,9,10}$ The e-beam seems to have advantages over the PLD process in that the cost per watt of the e-beam itself is at least 1000 times lower and the cost of raw materials is about half that of the PLD process. The latter comes from the fact that the e-beam process uses elemental Yttrium, Barium and Copper instead of the YBCO compound as in PLD. A disadvantage of the e-beam system is that it requires measurement of the concentration of $\mathrm{Y}, \mathrm{Ba}$ and $\mathrm{Cu}$ near the deposition site so that the amount being evaporated can be controlled to maintain the desired stoichiometry for formation of the correct YBCO compound. Also, the vacuum required in the deposition chamber is lower $\left(\sim 10^{-6} \mathrm{~mm} \mathrm{Hg} v s .10^{-3} \mathrm{~mm} \mathrm{Hg}\right.$ for PLD).

In this work element UTSI is tasked to evaluate promising production processes. The objective of this initial study is to compare the life cycle cost of a manufacturing facility using PLD versus a similar facility using electron beam deposition. Similar studies will be undertaken to compare these processes to other promising processes.

\subsection{Description of the Production Facility and Assumptions Used}

It is the intent of this study to compare costs in an era in which the coated conductor is fully commercial. An annual production rate of 18,000,000 meters/year was chosen as the production target. Many assumptions were chosen based on the "Research and Development Roadmap to Achieve Electrical Wire Advancements from Superconducting Coatings". ${ }^{11}$ Some 
key assumptions are listed in Table 2-1. The effects of key assumptions are evaluated by sensitivity analyses in the study.

\section{Table 2-1 Assumptions Used in the Study}

\begin{tabular}{|l|l|}
\hline Critical Current Density in the Superconductor: & $\begin{array}{l}10^{6} \mathrm{~A} / \mathrm{cm}^{2} \text { for self field, } \\
10^{5} \mathrm{a} / \mathrm{cm}^{2} \text { for } 5 \text { Tesla } \perp \text { field }\end{array}$ \\
\hline Plant Capacity: & $18,000 \mathrm{~km} / \mathrm{yr}$ \\
\hline Plant Lifetime: & 10 Years \\
\hline Wire Composition: & Shown in Figure 2-1 \\
\hline Annual Capital Charge: & $24.7 \%$, Including10\% Depreciation \\
\hline Capacity Factor: & $65 \%$ \\
\hline \multicolumn{2}{|l|}{ Deposition Rate High Enough to Permit a Single E-beam Chamber with $300 \mathrm{~kW}$ E-beams } \\
\hline
\end{tabular}
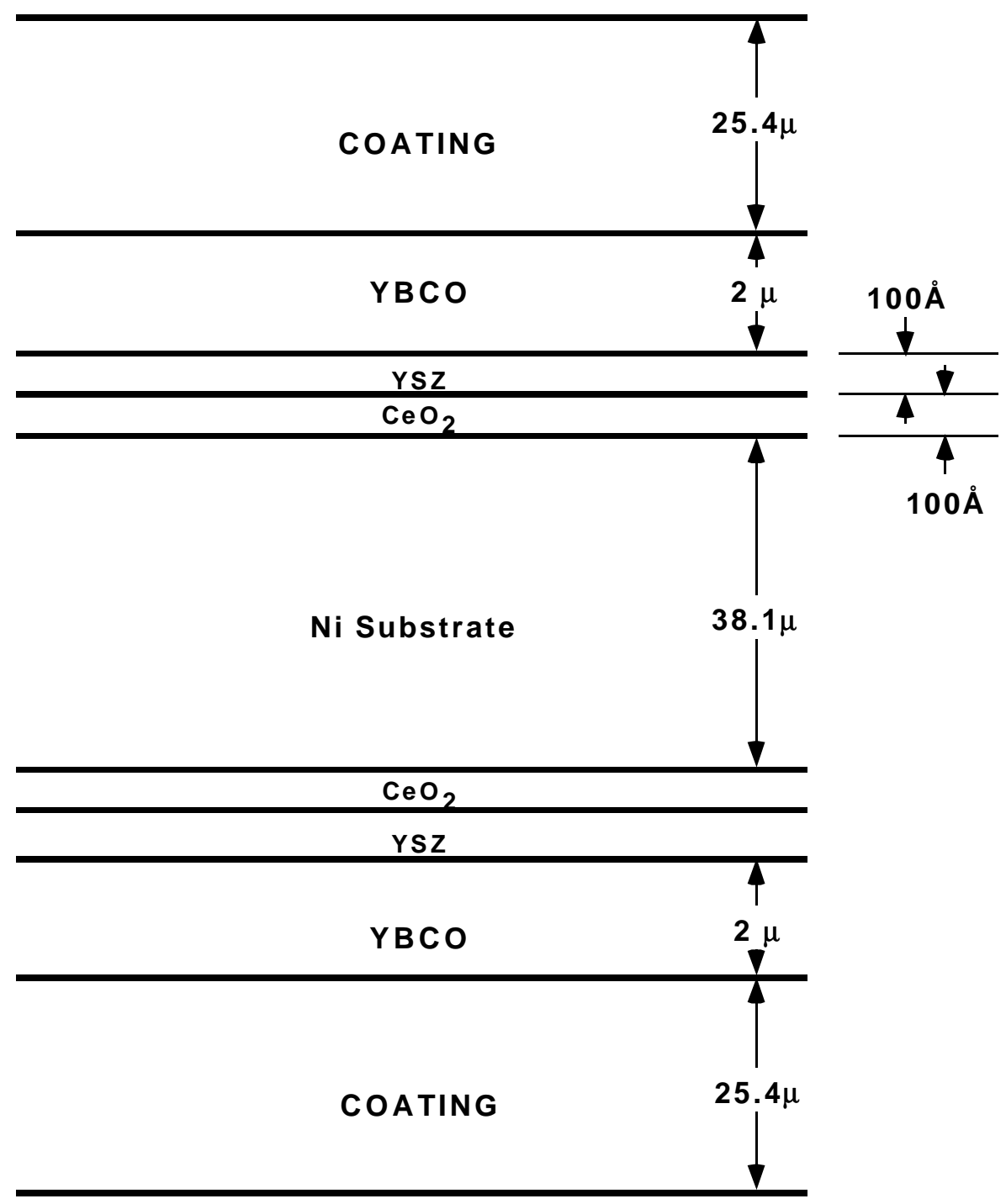

Figure 2.0-1 Assumed Conductor Configuration (Not to scale) 


\subsection{Substrate Production}

The plant choices under consideration vary only in the method of application of the YBCO superconductor layer. The initial step includes a rolling mill for high purity nickel, 10 stages, with 25\% reduction at each stage to reduce the nickel strip 95\% from its initial thickness of 762 microns ( 30 mils) to 38.1 microns $(1.5$ mils). The rolling mill includes a control system that measures the surface smoothness and thickness and implements control actions to keep the mill in tolerance. The rolled strip is stored on reels and batch annealed in an atmosphere of $96 \%$ argon and $4 \%$ hydrogen.

The textured nickel strip then is processed through two electron beam web coaters. The first applies a yttrium stabilized zirconia (YSZ) layer 100 Angstroms thick. (Note that one of the review comments was that this YSZ layer needs to be at least 2,000 Angstroms thick. ${ }^{12}$ This case is treated in a sensitivity analysis.) The second web coater applies a cerium oxide layer 100 Angstroms thick. The web coaters are near commercial products with Raman spectrometry added to evaluate the quality of the crystalline layers being deposited to assure layers adequate for epitaxial application of successive layers.

\subsection{Application of YBCO Superconductor by Electron Beam Vaporization}

The next manufacturing step is application of superconductor layers. The basic process requires heating the precursors and vaporizing them so that they are at the desired state for deposition. For the e-beam plant, multiple line beams separately vaporize yttrium, barium and copper and monotonic oxygen is provided to establish the correct oxygen stoichiometry. ${ }^{10}$ The concentration of each of the elements is measured by atomic absorption spectrometry and control applied to the electron beam to keep the concentration in tolerance. The crystalline structure is sampled by Raman spectroscopy and oxygen is controlled to achieve the desired compound. ${ }^{13}$ An assumed configuration for the electron beam chamber is shown in Figure 2.2-1. The requirements for a cooling roller and double-sided deposition force the use of two chambers or two segments in a single chamber as shown. In this configuration, the deposition area is $50 \mathrm{~cm}$ long by 30 tapes wide, each tape being $1 \mathrm{~cm}$ wide. Clearance between tapes is set at the minimal possible without mechanical interference. Assuming uniform flux of precursors in a hemisphere and a distance of the pots from the deposition surface area of $1.5 \mathrm{~m}$, the material utilization efficiency is calculated to be $10.6 \%$. The remainder condenses on the walls, shutters and other surfaces in the chamber. Following Hammond, ${ }^{10}$ monatomic oxygen is provided to facilitate the formation of optimum superconductor. The unused oxygen is expected to combine with the unused precursors in the wall deposits. What gaseous oxygen remains is pumped out by the vacuum pumps. This, and the fact that the electron beam chamber must be operated at a pressure below $10^{-6} \mathrm{~mm}$ of $\mathrm{Hg}$, increases the vacuum pump requirement for this system compared with the Pulsed Laser Deposition (PLD) system that operates at $10^{-3} \mathrm{~mm}$ of $\mathrm{Hg}$.

For the assumed production rate, a material utilization rate of $10.6 \%$ and based upon the best property data that could be found, the energy requirement for the electron beam process is 3,665 watts. This data is tabulated in Table 2.2-1. Of course, there are losses and other inefficiencies such as heat loss to the walls, heat loss to the water cooled walls of the pots and heating material that is never vaporized. Consequently, the power requirement shown should be 
considered an unattainable minimum but it does give a rough idea of the magnitude of the power needed from the electron beams.

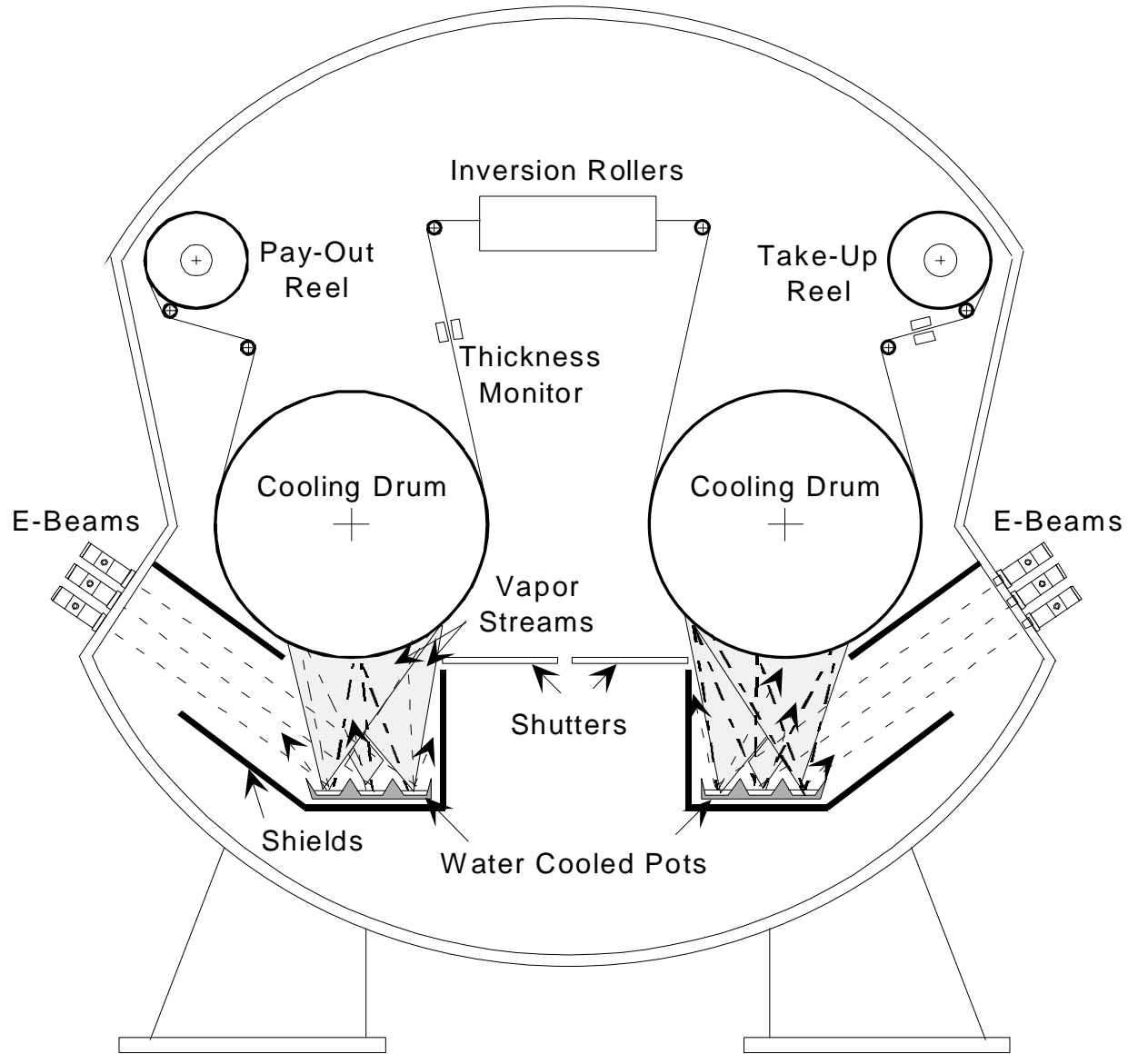

Figure 2.2-1 Concept for the Electron Beam Deposition Chamber

Table 2.2-1 Ideal Deposition Power Required

\begin{tabular}{|c|c|c|c|c|c|}
\hline $\begin{array}{c}\text { Element and } \\
\text { Vaporization } \\
\text { Temperature } \\
\text { at } 10^{-6} \text { torr }(\mathrm{K})\end{array}$ & $\begin{array}{c}\text { Mass at } \\
\text { Substrate } \\
(\mathrm{gm} / \mathrm{hr})\end{array}$ & $\begin{array}{c}\text { Mass to be } \\
\text { Vaporized } \\
(\mathrm{gm} / \mathrm{hr})\end{array}$ & $\begin{array}{c}\text { Power to } \\
\text { Vaporization } \\
\text { Temperature } \\
(\mathrm{W})\end{array}$ & $\begin{array}{c}\text { Power for } \\
\text { Vaporization (W) }\end{array}$ & $\begin{array}{c}\text { Total Power } \\
\text { Required (W) }\end{array}$ \\
\hline $\mathrm{Y}, 1246$ & 72 & 677 & 51 & 732 & 783 \\
\hline $\mathrm{Ba}, 900$ & 222 & 2,096 & 68 & 655 & 723 \\
\hline $\mathrm{Cu}, 1130$ & 154 & 1,459 & 152 & 2,007 & 2,159 \\
\hline Total & 448 & 4,232 & 271 & 3,394 & 3,665 \\
\hline
\end{tabular}

The efficiency of utilization of the electron beam power in this process is unknown. Hammond used $300 \mathrm{~kW}$ for depositing roughly one third of the amount required by this plant. ${ }^{8}$ Actual efficiencies will have to be measured experimentally. Fortunately, most commercial electron beam generators are adjustable over a wide range of beam powers. One of the major 
heat losses is to the walls of the boats from the molten precursors. The recommended boat material for barium and yttrium is tungsten. Molybdenum is recommended for copper. Both of these boat materials should be able to withstand the maximum temperature of the molten solids and reduce the beam power requirement. For this study, an assumption is made that the efficiency will be high enough to use $300 \mathrm{~kW}$ of beam power made up with six $50 \mathrm{~kW}$ beams. The efficiency is thus $3.665 \mathrm{kw} / 300 \mathrm{kw}=1.2 \%$. Since the electron beam cost is a small portion of the plant cost, the results are relatively insensitive to this assumption.

\subsection{Application of the YBCO Superconductor by Pulsed Laser Deposition}

Pulsed laser deposition concentrates a small amount of energy (typically less than a Joule) onto a very small spot of the target over a short period. The incident laser energy initially vaporizes a thin layer of the target and subsequently produces a pulse of particulate that has stoichiometry representative of the target within a reasonable beam width. The vaporized material has been found to not be stoichiometric as the target material, but the solid particulate flux is stoichiometric within reasonable limits of applied power density. The geometry method is shown in Figure 2.3-1. Venkatesan ${ }^{21}$ has shown that the particle flux is stoichiometric for $\theta= \pm 20^{\circ}$ in applying YBCO. This value is used in the subsequent calculations as the limit for angular coverage, however, it is to be expected that this is also a function of the required power density used.

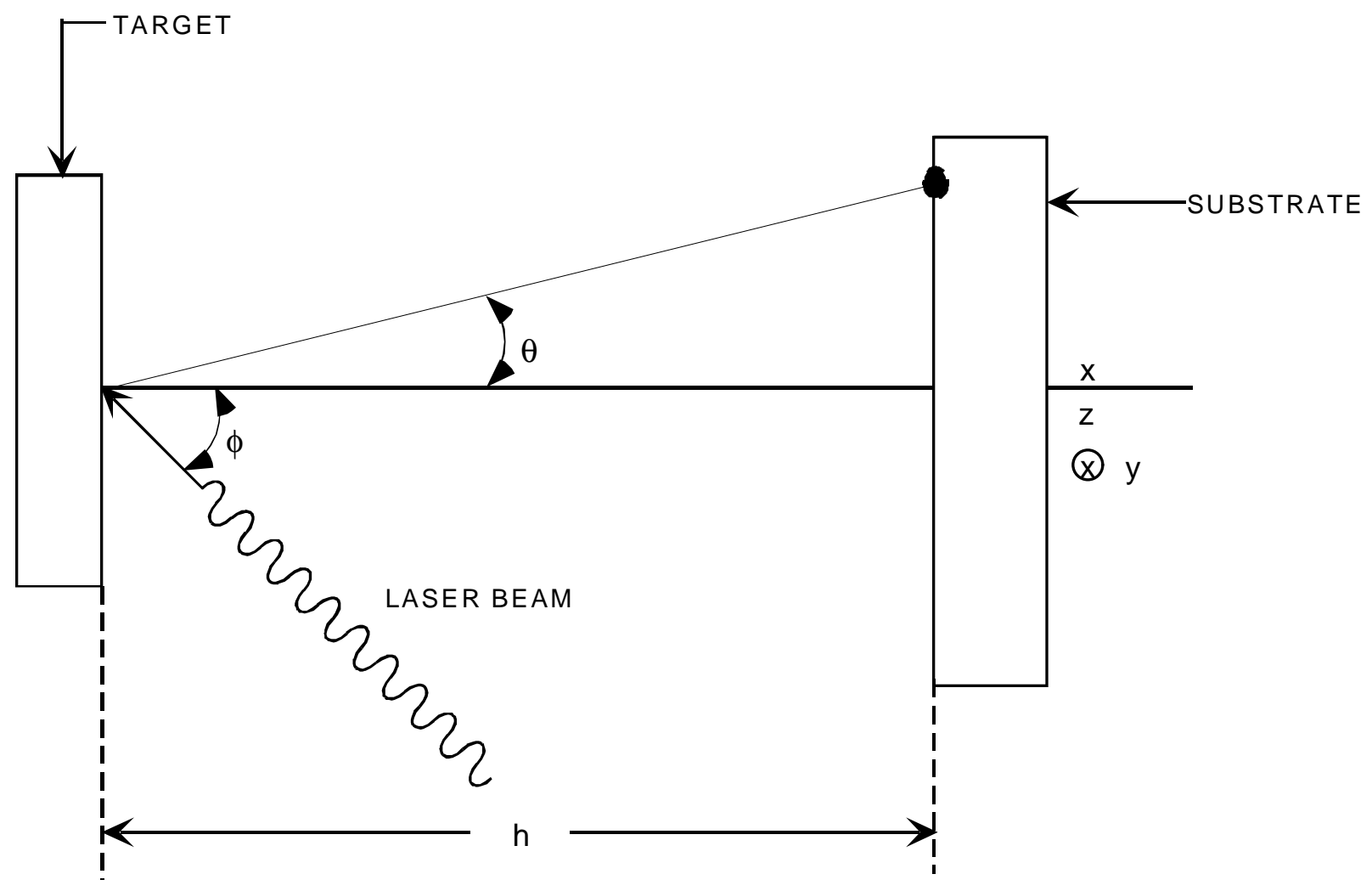

Figure 2.3-1 Geometry for PLD 
The distribution of laser energy on the substrate and the resulting particle flux on the substrate can be controlled to some extent by careful design. A rectangular pattern would seem to be most desirable for a tape in motion as the particle flux variations in the direction of travel would average out as the tape traverses the region of deposition. However, in the other direction the variation would produce films of lesser thickness. One approach to this problem might be to have the plant produce wire having a range of superconductor thickness and current carrying capacity. For this study, a vertical deposition region is used that results in $\pm 10 \%$ thickness variation. From a typical material distribution function:

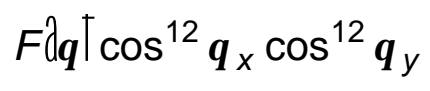

The material utilization efficiency of the material removed from the target can be expressed as:

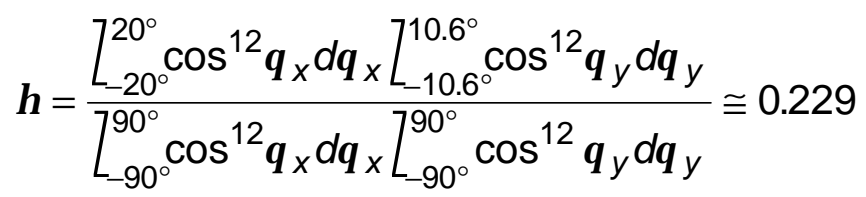

Since a good surface is needed on the target, it is not possible to utilize $100 \%$ of the YBCO in the pot. Utilization of $70 \%$ has been suggested as a goal. If this is assumed, the overall material utilization efficiency becomes: $(.229)(.7)=.16$.

The next issue that must be addressed is the energy efficiency of the laser beam. The total mass of YBCO to be deposited at the substrate is 448 grams/hour. Using the $22.9 \%$ efficiency calculated above for target to substrate transfer, $448 \mathrm{gms} / \mathrm{hr} / .229=1,956 \mathrm{gms} / \mathrm{hr}$ must be dislodged from the target into the beam. The question of how much incident power is required to dislodge this amount of YBCO is difficult if for no other reason than the effect of producing the particulate flux is unknown. Data from laboratory experiments give generally unfavorable indications. For example, Venkatesan $1988^{21,14}$ shows $1.14 \times 10^{-5}$ grams/Joule of energy and Munchausen ${ }^{22,14} 1990$ shows $3.75 \times 10^{-6}$ grams/Joule (using the average incident energy of $3.5 \mathrm{Joules} / \mathrm{cm}^{2}$ ). If one chooses an excimer laser having $200 \mathrm{pulses} / \mathrm{sec}$ of 1 Joule/pulse, the number of lasers required would be 240 and 725, respectively. This is a key issue as this number of lasers with their accompanying vacuum chambers and instrumentation would almost certainly not be economical in a large scale production facility. Based on engineering the system for production, rather than experiment, the base case is chosen at 3 times the rate of Venkatesan 1988, or $3.4 \times 10^{-5}$ grams/Joule. This implies 80 lasers, operating at 200 pulses/sec with energy level of 1 Joule/pulse.

It does not appear feasible to have a single chamber with 80 lasers radiating the YBCO target. The limit of practicality seems to be about five laser ports. However, with this level of power (a maximum of 1,000 watts) this substrate will likely need heating to get the optimum deposition temperature rather than cooling as in the electron beam case. This opens up the feasibility of simultaneous, double-sided coating. Surface temperature heating would be by radiant lamps. With this concept, 5 lasers could be arranged on each side of a vertically positioned substrate (See Figure 2.3-1). The production rate would then require eight chambers in parallel. Figure 2.3-2 shows the concept used for cost calculation. 


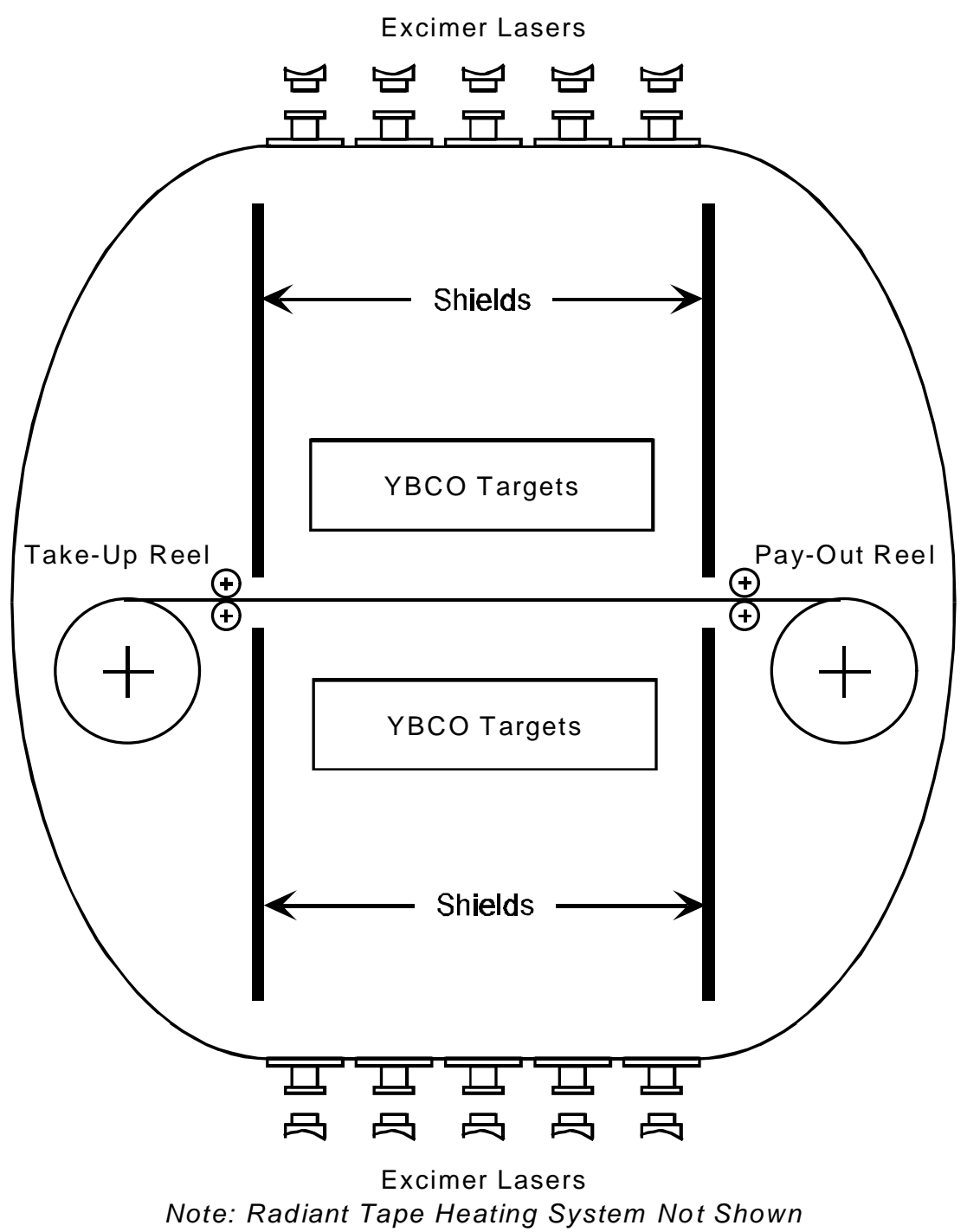

Figure 2.3-2 Pulsed Laser Deposition Concept

\subsection{Passivation/Insulation Layer}

It is necessary to provide a layer to protect the superconductor tape from the influences of the environment in which it will be used and to provide electrical insulation from ground or other potentials. Very little work has been done on optimizing this layer for thin film superconductors. It is likely that the optimum layer to meet the requirement will depend upon the application for the superconductor. For this study, it has been assumed that the wire is insulated in a manner similar to current copper magnet wire. The capital costs include equipment to dip and dry, patterned after enamel application to copper wires used for motor windings. The material cost is considered negligible. As this requirement is developed in more detail, costs may need to be added to perform this function. 
The estimate of capital cost for the plants described are tabulated in Table 3.0-1. In this section, the source and logic for these cost estimates are discussed.

The rolling mill estimate was obtained from a manufacturer ${ }^{15}$ and provides for a ten stage mill that will reduce $25 \%$ at each stage or $95 \%$ overall. The estimate is for operation in air. The mill can be provided to work in inert gas if required, but at additional cost. The annealing furnace cost estimate was derived from a chemical engineering handbook ${ }^{16}$ and adjusted for price inflation $^{17}$ and capacity. It is to be capable of operating in a mixture of $96 \%$ inert gas with $4 \%$ hydrogen. The capacity is $600 \mathrm{~km}$ per charge. The estimate for two electron beam web coaters to apply the $\mathrm{YSZ}$ and $\mathrm{CeO}_{2}$ buffer layers was based on data from the American Thin Film Company. ${ }^{18}$

Table 3.0-1 Capital Cost Estimates for the Plant

\begin{tabular}{|l|r|r|}
\hline \multicolumn{1}{|c|}{ Cost Category } & Electron Beam $(\$)$ & \multicolumn{1}{|c|}{ PLD (\$) } \\
\hline Rolling Mill & 150,000 & 150,000 \\
\hline Heat Treatment Facility & 443,000 & 443,000 \\
\hline E-Beam Web Coater & $4,000,000$ & $4,000,000$ \\
\hline E-Beam-YBCO & $1,419,000$ & 0 \\
\hline PLD-YBCO & 0 & $41,500,000$ \\
\hline Vacuum Chamber for YBCO & $1,382,616$ & $5,330,600$ \\
\hline Monatomic Oxygen System & 402,000 & 0 \\
\hline Oxygen Monitor & 52,000 & 0 \\
\hline Environmental Treatment & 100,000 & 100,000 \\
\hline Passivation/Insulation & $1,000,000$ & $1,000,000$ \\
\hline Tape Handling System & 500,000 & 500,000 \\
\hline Control Systems & $6,209,000$ & $4,109,000$ \\
\hline Laboratory/.QA Test Facility & $1,500,000$ & $1,500,000$ \\
\hline Site \& Development & 550,000 & 550,000 \\
\hline Electrical Substations & $1,000,000$ & $1,000,000$ \\
\hline Buildings & $3,720,000$ & $3,720,000$ \\
\hline Sub Total & $22,427,616$ & $63,902,600$ \\
\hline AE Fee @ 15\% & $3,364,142$ & $9,585,390$ \\
\hline & & \\
\hline Sub Total & $25,791,758$ & $73,487,990$ \\
\hline Contingency @ 20\%, \$ & $5,158,352$ & $14,697,598$ \\
\hline & & $88,185,588$ \\
\hline Total Capital Cost, \$ & $30,950,110$ & \\
\hline
\end{tabular}

The vacuum chamber cost for electron beam deposition was derived from the Kurt J. Lesker Company Vacuum Products Catalog and scaled to $60 \mathrm{~cm}$ diameter. It was then doubled for two-sided application. The cost includes six $50 \mathrm{~kW}$ electron beams at a quoted price of $\$ 1.20 /$ watt of beam power. ${ }^{19}$ The monatomic oxygen system and oxygen monitor costs are taken from Hammond ${ }^{8}$ and scaled as required. 
As previously noted, 80 excimer lasers power the PLD deposition system. The cost is based on a quoted price from the manufacturer. The vacuum chamber for PLD needs to be 60 $\mathrm{cm}$ in diameter but the tape can be mounted vertically for simultaneous application of both sides on the same pass. The higher operating pressure and the absence of an auxiliary oxygen supply simplify the chamber compared with the electron beam case. The source of basic cost data is the same as for the electron beam chamber.

The environmental control system for plants using either of these processes should be very simple. Most of the unused precursors will condense on the walls and shields in the chambers and will need to be cleaned off periodically. Any remaining particulate will be filtered out before entering the vacuum pumps. No disposal costs for the solid precursor have been included because it is anticipated that the material will be marketable for recycling. The only known gaseous pollutant is the hydrogen used in annealing the metal substrate. The cost reflects a small, gas assisted flare stack to which all the gases pumped from chambers and the annealing furnaces would be routed.

The passivation/insulation system is largely undetermined. The capital cost included represents a rough engineering estimate of the cost of a 'dip and dry' system similar to that used on copper magnet wire. The tape handling system is likewise not a refined cost estimate but a rough estimate. Handling this thin tape reliably is an important issue for the success of the plant.

The process control system costs are a combination of engineering estimates and values derived from references. Table 3.0-2 lists the components of this estimate.

Table 3.0-2 Process Control System Cost Estimates

\begin{tabular}{|l|r|r|}
\hline \multicolumn{1}{|c|}{ Control Sought } & \multicolumn{1}{c|}{$\begin{array}{c}\text { Electron Beam } \\
\text { Plant }\end{array}$} & \multicolumn{1}{c|}{ PLD Plant } \\
\hline Rolling and Annealing & 59,300 & 59,300 \\
\hline Crystal Quality, $\mathrm{O}_{2}$ Content & 200,000 & 200,000 \\
\hline Surface Smoothness & 50,000 & 50,000 \\
\hline Stoichiometry in E-Beam System & $2,100,000$ & $3,600,000$ \\
\hline Overall Process Control & $3,600,000$ & \\
\hline & & $4,109,300$ \\
\hline Total Process Control & $6,209,000$ & \\
\hline
\end{tabular}

The laboratory and quality assurance costs include general-purpose laboratory equipment including $\mathrm{x}$-ray diffraction, scanning electron microscope, superconductivity test set and atomic force microscopy equipment. The major QA expense is for a capability to final test a reel of cable at liquid nitrogen temperature for critical current.

The site is 10 acres of land with driveways, parking areas and lighting. The metal building is sized at $100,000 \mathrm{ft}^{2}$ and estimated ${ }^{20}$ at $\$ 37.20 / \mathrm{ft}^{2}$. The size of the substation, $25 \mathrm{MWe}$ and the costs are engineering estimates. 
The architect-engineer fee is estimated at $15 \%$ of the total plant and equipment cost. It is anticipated that this will involve an architect for the building and grounds and a specialized engineering firm for the production process equipment.

Finally, a contingency of $20 \%$ is included. It is anticipated that this will be a real cost and the amount is not believed to be excessive, even assuming that this technology is fully developed. In fact, a review comment was received that it might be appropriate to include a process contingency in addition to the plant contingency. However, since this study assumes that the technology has been developed and proven, no process contingency was included.

\subsection{Process Material Costs}

The estimated costs for consumables for both processes are listed in Table 4.0-1. The prices used are derived from estimates by current suppliers for quantities required for this plant. A material utilization efficiency of $10.6 \%$ is assumed for the electron beam process and $16 \%$ for the PLD Process.

Table 4.0-1 Consumable Cost for Assumed Production

\begin{tabular}{|l|r|r|r|}
\hline \multicolumn{2}{|c|}{} & \multicolumn{1}{c|}{ E-Beam } & \multicolumn{1}{c|}{ PLD } \\
\hline Materials Cost & Unit Cost $(\$)$ & Annual Cost $(\$)$ & Annual Cost (\$) \\
\hline Yttrium & $38.27 / \mathrm{kg}$ & $2,330,000$ & $2,330,000$ \\
\hline Barium & $345 / \mathrm{kg}$ & $2,049,000$ & \\
\hline Copper & $124 / \mathrm{kg}$ & $2,300,000$ & 79,082 \\
\hline Cerium & $41 / \mathrm{kg}$ & 523,560 & 246,865 \\
\hline YSZ & $394 / \mathrm{kg}$ & 79,082 & $8,836,425$ \\
\hline YBCO & $1,298 / \mathrm{kg}$ & 246,865 & 500,000 \\
\hline Gases, Supplies & $300 / \mathrm{kg}$ & & $11,992,372$ \\
\hline
\end{tabular}

\subsection{Production Cost Estimates}

The capital costs as shown in Table 3.0-1 result in annualized capital costs that include depreciation of the plant and equipment, interest on capital, taxes and working capital. Table 5.0-1 shows the factors used to derive the $24.7 \%$ annual cost rate for the base case of this study.

Table 5.0-1 Annual Capital Charge Components

\begin{tabular}{|l|c|}
\hline Cost of Money & $7.5 \%$ \\
\hline Income Taxes & $4.1 \%$ \\
\hline Depreciation, 10 years s/1 & $10 \%$ \\
\hline Other Taxes & $2.8 \%$ \\
\hline Working Capital & $0.2 \%$ \\
\hline
\end{tabular}


The labor costs are based on the staffing shown in Table 5.0-2 and an average labor rate of $\$ 25.00 /$ hour plus $26 \%$ for fringe benefits. The production cost summary is shown in Table 5.0-3. An annual allowance of $10 \%$ of the total capital cost is included for maintenance of plant and equipment. The materials cost is as listed in Table 4.0-1. Electricity and other utility costs are based on an engineering estimate and an overall cost of electricity of $\$ 60.00 / \mathrm{MWh}$.

Table 5.0-2 Staffing Basis for the Plants Under Consideration (units are number of employees)

\begin{tabular}{|l|c|c|}
\hline & E-BEAM & PLD \\
\hline YBCO Application & 4 & 8 \\
\hline Rolling \& Annealing Substrate & 2 & 6 \\
\hline Web Coating Buffers & 2 & 2 \\
\hline Environmental Cleanup & 2 & 2 \\
\hline Plant Maintenance & 4 & 4 \\
\hline Janitorial & 1 & 1 \\
\hline Shift Manager & 2 & 2 \\
\hline Engineer & 2 & 1 \\
\hline Receiving \& Incoming Material & 27 & 30 \\
\hline Shipping \& Materials Management & 132 & 147 \\
\hline Totals/Shift & 2 & 2 \\
\hline Total Shift Workers* & 2 & 2 \\
\hline Secretary/Accountant & 137 & 1 \\
\hline Purchasing Personnel & 2 & 2 \\
\hline Plant Manager & 2 & \\
\hline Total Labor & 2 & \\
\hline
\end{tabular}

* For Continuous Operation, Multiply by $24 X 365 / 1792=4.89$

With the annual cost of the plant and the annual production, the cost per meter of production is obtained as $\$ 1.71 / \mathrm{m}$ for the electron beam process and $\$ 3.09 / \mathrm{m}$ for the PLD process. If the goal of critical current density of $10^{6}$ amperes $/ \mathrm{cm}^{2}$ is achieved in self magnetic field, the critical current for the wire will be 400 amperes. This gives a cost per kiloamperemeter of $\$ 4.28$ and $\$ 7.72$, respectively.

At the critical current density of $10^{5}$ amperes $/ \mathrm{cm}^{2}$ which is the plan goal in a 5 Tesla magnetic field perpendicular to the direction of current flow, the critical current would be 40 amperes and the cost/ kA-m would be $\$ 42.75$ and $\$ 77.25$, respectively. 
Table 5.0-3 Production Cost Summary

\begin{tabular}{|l|r|r|}
\hline & E-Beam Process (\$) & Pulsed Laser Process(\$) \\
\hline Total Capital Cost & $30,950,110$ & $88,185,588$ \\
\hline Annual Capital Charges @ 24.7\% & $7,644,677$ & $21,781,840$ \\
\hline Maintenance @ 10\% of Capital Cost & $3,095,011$ & $8,818,559$ \\
\hline Materials Cost, \$/year & $8,028,507$ & $11,992,372$ \\
\hline Labor, \$/year & $9,013,486$ & $9,974,664$ \\
\hline Electricity, Other Utilities, \$/yr. & $3,000,000$ & $3,000,000$ \\
\hline Total Annual Cost, \$ & $30,781,681$ & $55,567,488$ \\
\hline Annual Production, Meters & $18,000,000$ & $18,000,000$ \\
\hline Critical Current Amperes* & $400 / 40$ & $400 / 40$ \\
\hline Cost, \$/Meter & 1.71 & 3.09 \\
\hline Cost, \$/Kiloampere Meter* & $4.28 / 42.75$ & $7.72 / 77.18$ \\
\hline
\end{tabular}

* First number is for $J_{c}=10^{6} \mathrm{~A} / \mathrm{cm}^{2}$, second is for $10^{5} \mathrm{~A} / \mathrm{cm}^{2}$

\subsection{Sensitivity Analyses}

The purpose of this section is to examine the sensitivity of the result to some key assumptions. For illustrative purposes these analyses use the $\mathrm{J}_{\mathrm{c}}=10^{6} \mathrm{~A} / \mathrm{cm}^{2}$ case, which is the goal for conductors in self-field. Results can be applied for other current densities by multiplying the cost by the ratio of critical current densities.

\subsection{Cost Sensitivity to Deposition Rate}

The assumption that the deposition rate is adequate for production of the rated capacity with one electron beam deposition chamber for YBCO is equivalent to a deposition rate of 1,168 $\AA / \mathrm{s}$. Although there are reports in the literature of deposition at rates up to $10,000 \AA / \mathrm{sec}$, the general evidence seems to indicate that there is a trade-off in quality (as measured by critical current density) and deposition rate. The cost sensitivity of a lower deposition rate is primarily that additional deposition chambers with related equipment would be required. That is, if only half the deposition rate can be achieved at the desired quality, two parallel deposition chambers would be required, etc. The results of this first order cost change are shown on Figure 6.1-1.

\subsection{Cost Sensitivity to Capacity Factor}

The capacity factor is defined as the annual output of the plant divided by the theoretical output if the plant operated continuously for the year at rated throughput. The cost sensitivity is calculated by letting the output vary in accordance with capacity factor. The $18,000,000 \mathrm{~m} / \mathrm{yr}$ nominal design point is at $65 \%$ capacity factor. Figure 6.2-1 plots the results for both plants. 


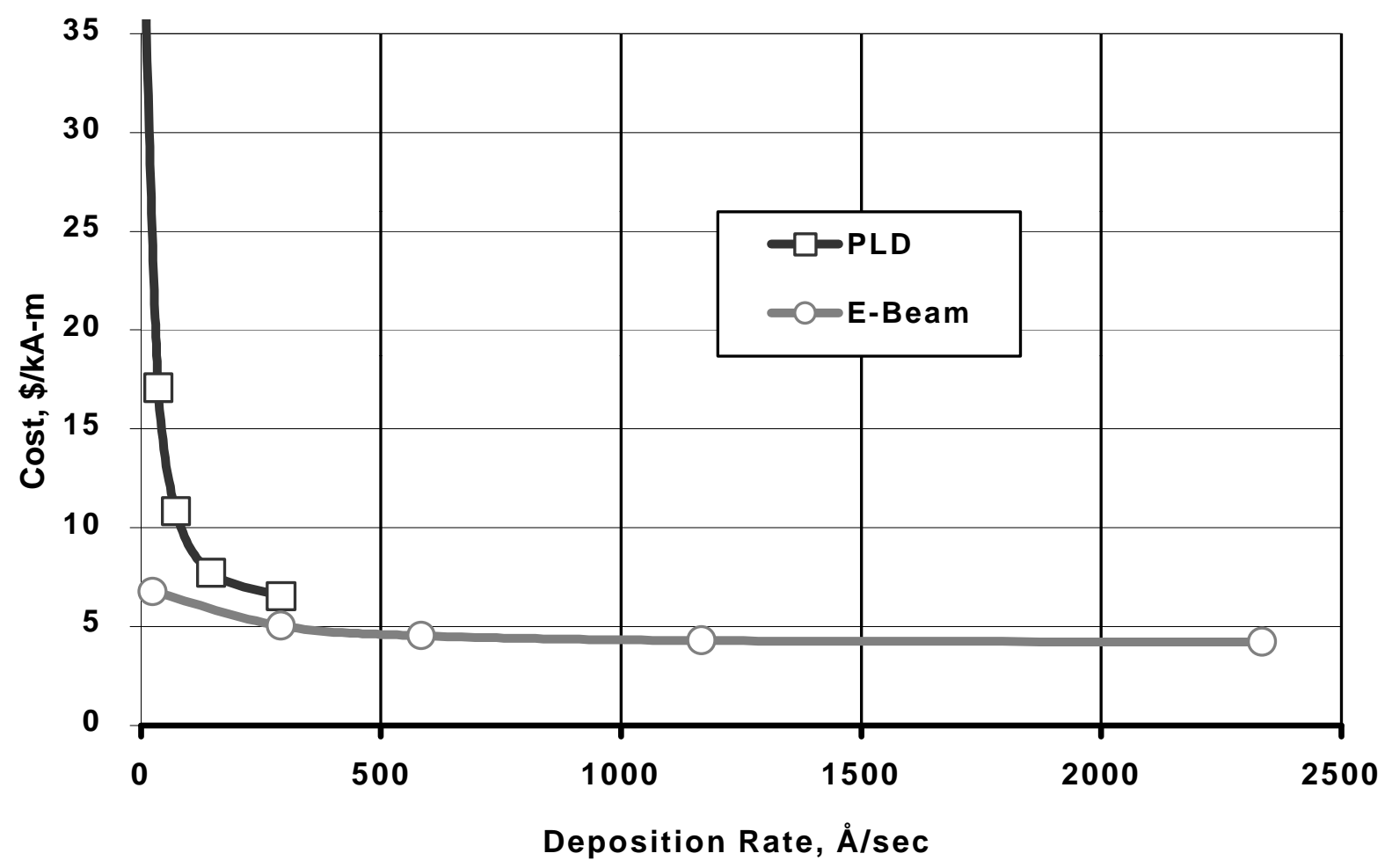

Figure 6.1-1 Cost Sensitivity to Deposition Rate

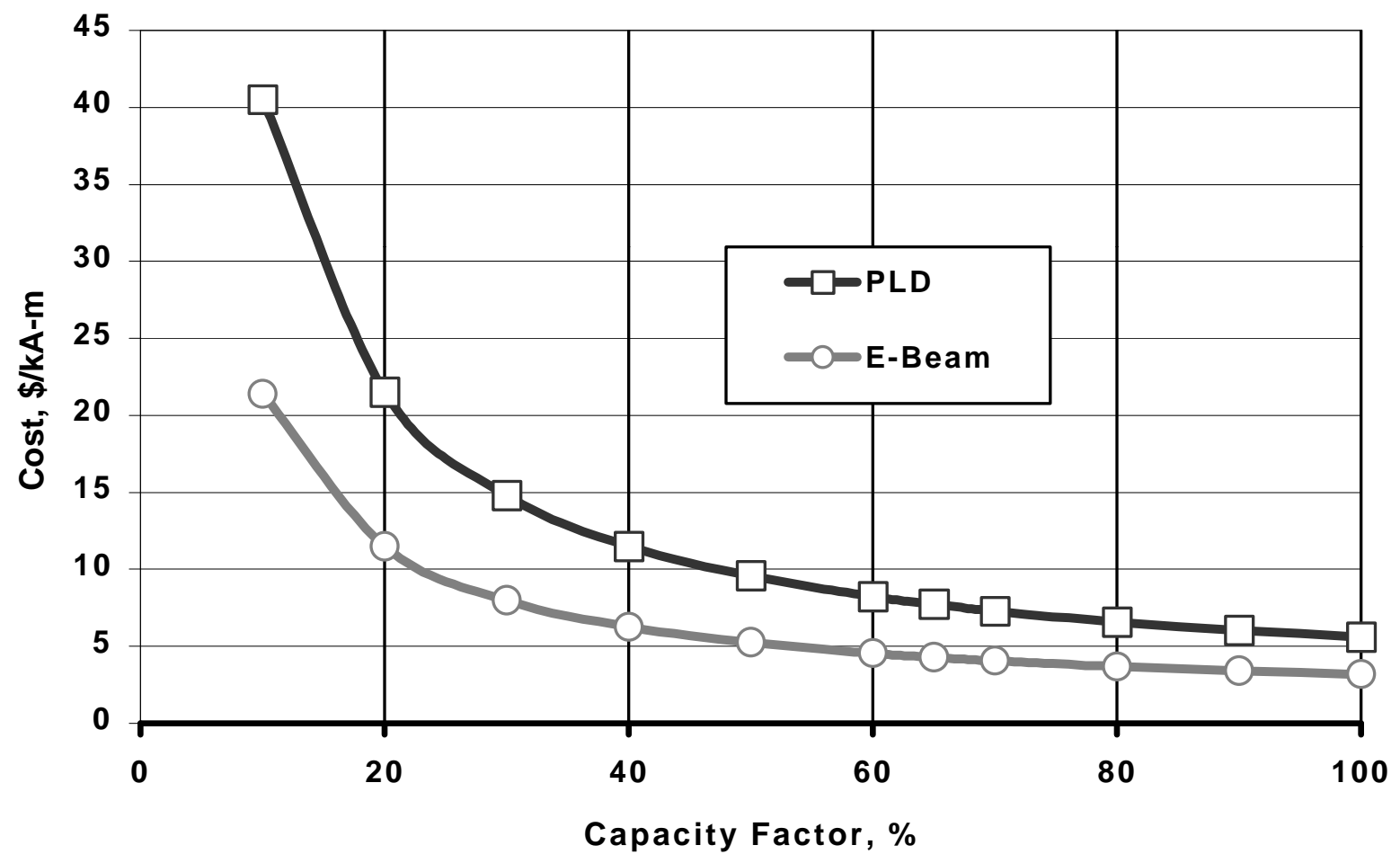

Figure 6.2-1 Cost Sensitivity to Capacity Factor 


\subsection{Life of Plant Cost Sensitivity}

The cost effect of varying plant life is in the depreciation that is a component of the annual charges for capital costs. The depreciation method used is straight line. The base case plant life of 10 years resulted in a $10 \%$ annual depreciation. The resulting cost sensitivity is shown in Figure 6.3-1.

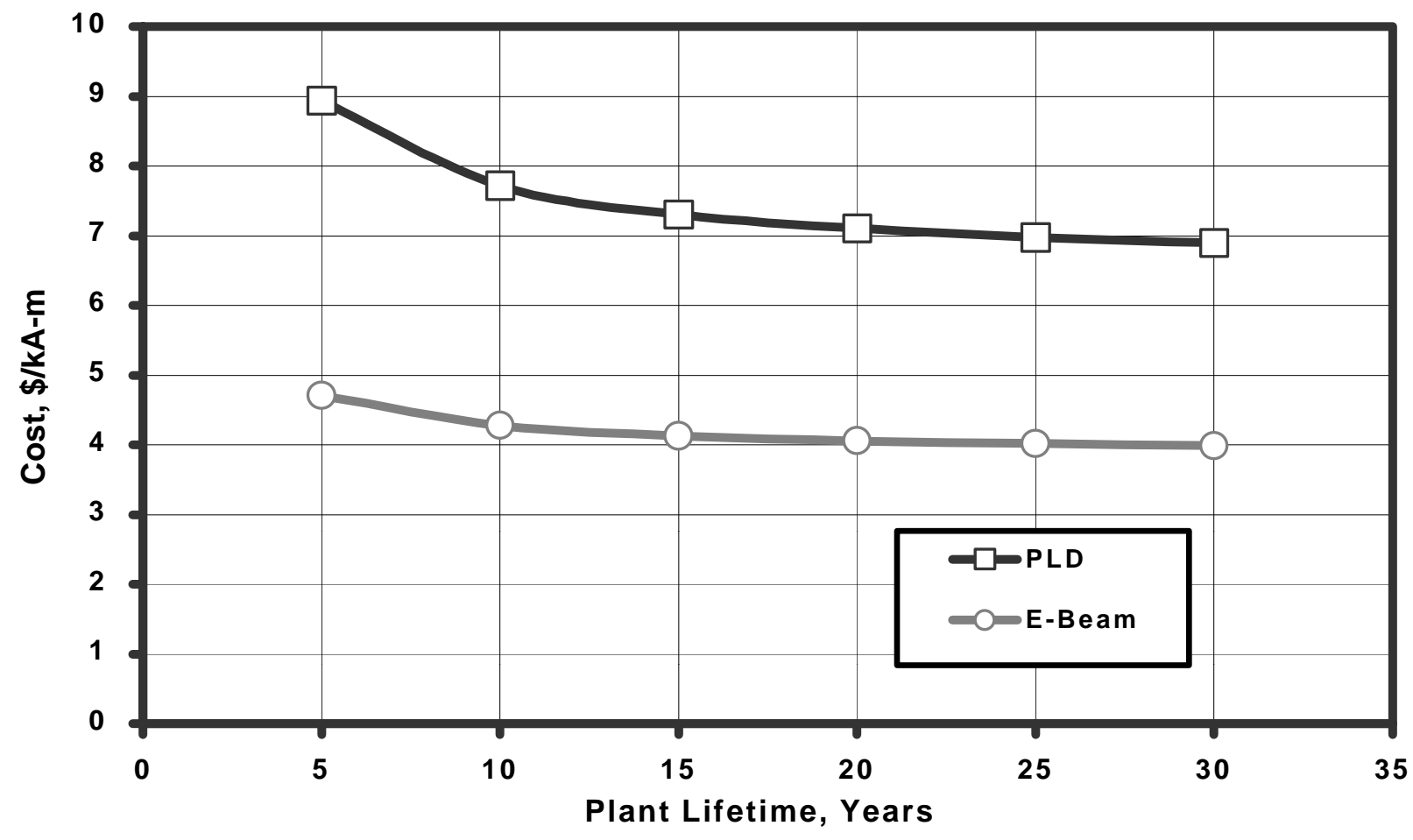

Figure 6.3-1 Cost Sensitivity to Plant Lifetime

\subsection{Sensitivity to Critical Current Density}

The critical current density achieved is an important factor because it inversely affects the number of wires required to carry a specified current and thus affects the cost per kiloampere-m. The calculated costs for a range of current densities are shown on Figure 6.4-1 on the following page.

\subsection{Cost Sensitivity to Material Utilization Rate}

The material utilization rate expresses the fraction of the purchased material that becomes part of the superconductor or buffer layer. The base case used for these calculations was $10.6 \%$ for the electron beam process and 16\% for PLD. Primary ways that this material is lost is by deposition on walls and shields in the vacuum chamber and by remaining in the pot or target after it is replaced. The cost effect of various utilization factors is shown on Figure 6.5-1, on the following page. 


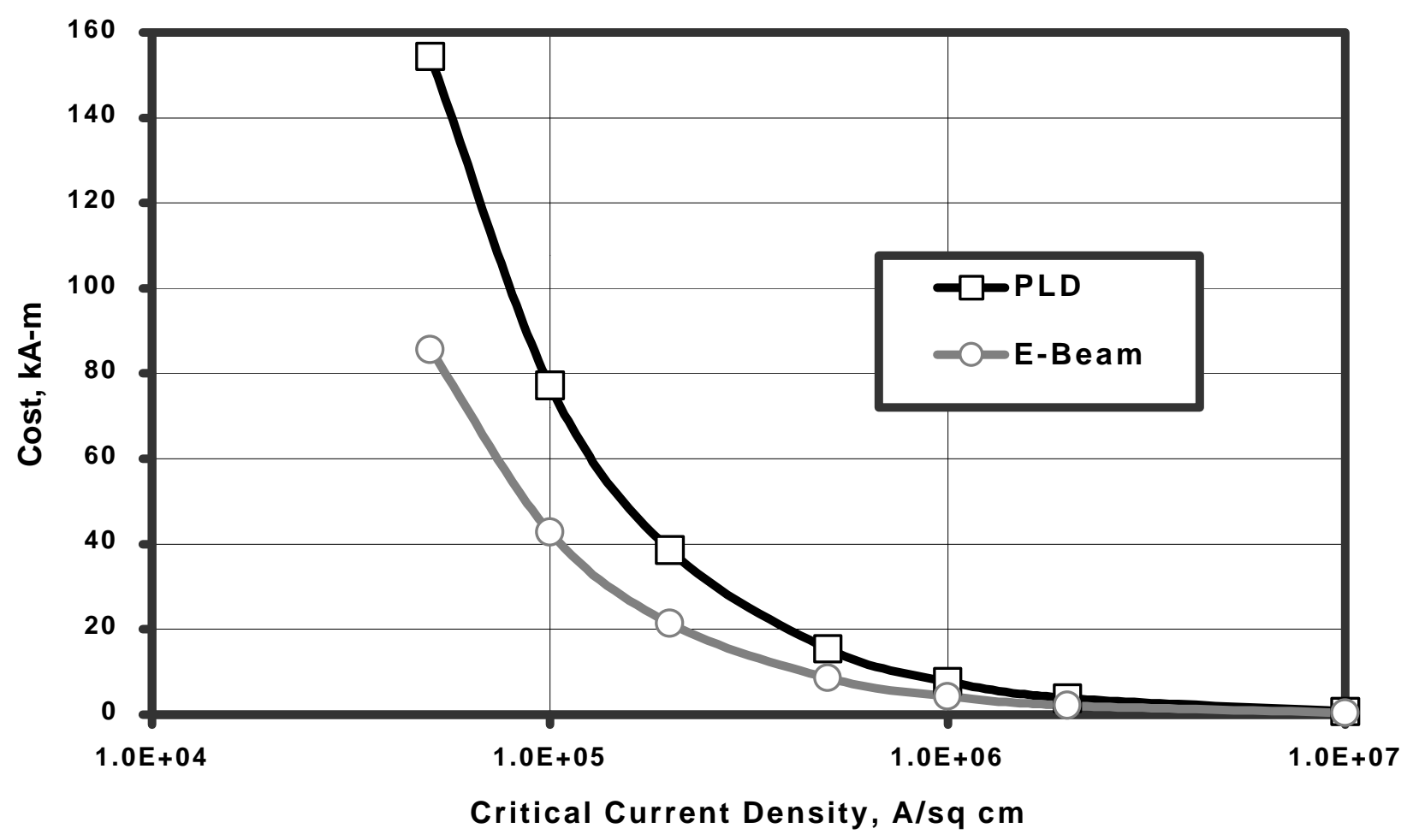

Figure 6.4-1 Cost Sensitivity to Critical Current Density

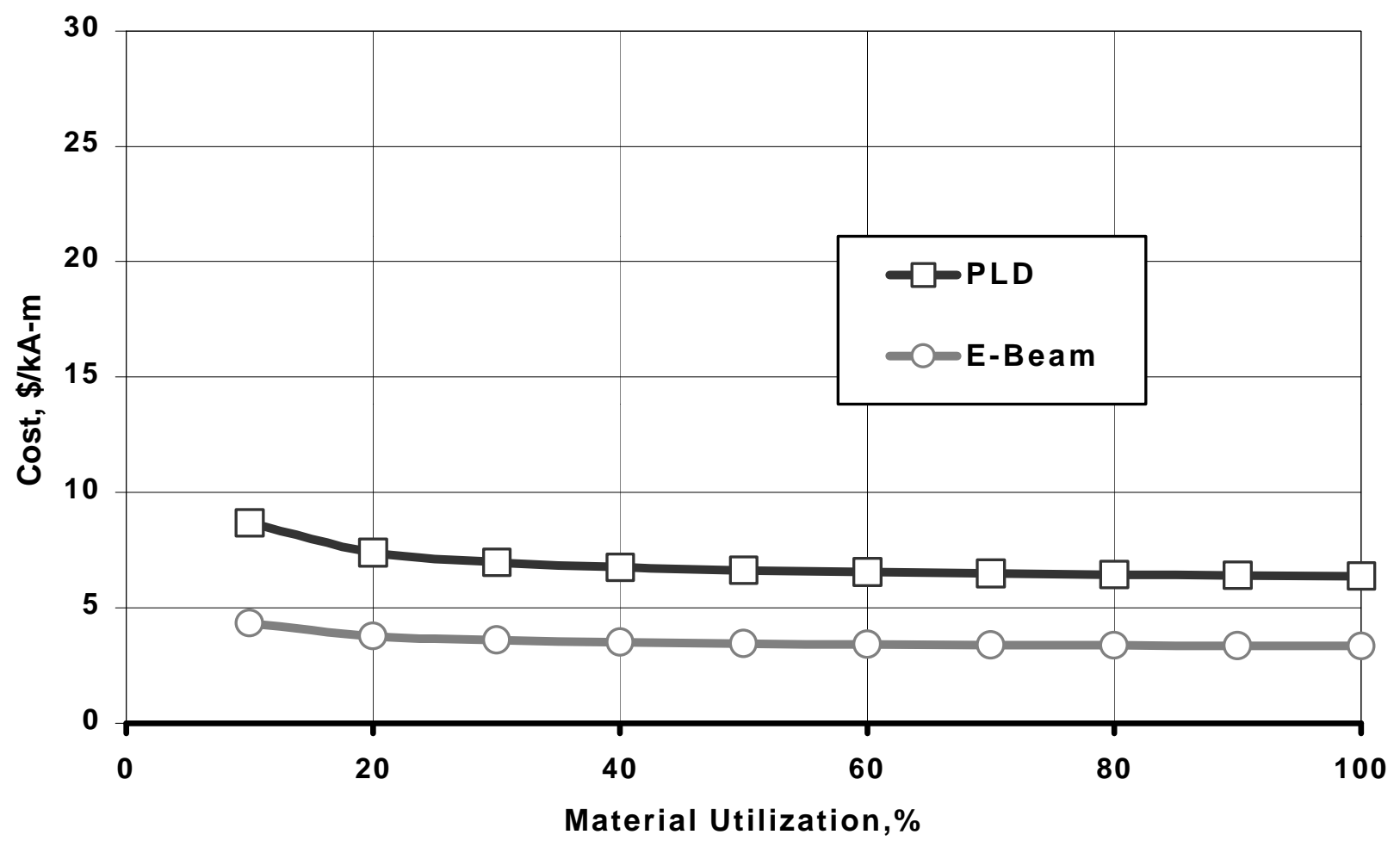

Figure 6.5-1 Cost Sensitivity to Material Utilization Fraction 


\subsection{Sensitivity to Use of a Thicker Layer of Yttrium Stabilized Zirconia (YSZ)}

One of the review comments received when this study was briefed in the early draft stage was that the YSZ layer will need to be thicker. ${ }^{12}$ It was suggested that it might need to be 2000 $\AA$ thick rather than the $100 \AA$ as used in the base case. The impact of a thicker layer on cost includes the additional material used and six additional electron beam web coaters to work in parallel in application of the YSZ buffer layer. The cost impact for a $2000 \AA$ layer is shown in Table 6.7-1.

Table 6.6-1 Cost Impact of Requiring a 2,000 ̊ Thick YSZ Buffer Layer (Base Case Cost in Parenthesis)

\begin{tabular}{|l|c|c|}
\hline & Electron Beam & PLD \\
\hline Cost $\$ / \mathrm{m}$ & $2.29(1.71)$ & $3.67(3.09)$ \\
\hline Cost $\$ / \mathrm{kA}-\mathrm{m}$ & $5.72(4.28)$ & $9.17(7.72)$ \\
\hline
\end{tabular}

\subsection{Sensitivity to Thickness of Superconducting Layer}

The base case assumed conductor shown in Figure 2.0-1 has a thickness of YBCO superconducting layer of only $2 \mu$ on each side. This is based on indications from experimental results that the crystalline structure for thicker layers deviates from that desired and the incremental critical current density declines. For the substrate, buffer and coating thickness chosen, the fill factor (defined as the ratio of superconductor to total cross section areas) is only $4.3 \%$. This is well below the $10 \%$ goal established in the plan ${ }^{11}$. It will be very difficult to meet that fill factor goal unless thicker superconductor layers can be used as the substrate and coating cannot be reduced in thickness much without compromising desired characteristics. If the technology to use thicker layers is available, improved fill factors and lower cost/kA-m can be achieved. Table 6.8-1 below illustrates the effect of using higher thicknesses of superconductor on the cost, which includes additional YBCO or YBCO precursors, plus additional YBCO application machinery. Other dimensions remain as in Figure 2.0-1.

Table 6.7-1 Effect of Increased Superconductor Layer Thickness

\begin{tabular}{|r|r|r|r|r|r|r|}
\hline \multicolumn{4}{|c|}{} & \multicolumn{2}{c|}{ E-Beam Process $(\$)$} & \multicolumn{2}{c|}{ PLD $(\$)$} \\
\hline $\mathrm{t}, \mu$ & $\mathrm{FF}(\%)$ & \multicolumn{1}{c|}{$\mathrm{I}_{\mathrm{c}}(\mathrm{a})^{*}$} & \multicolumn{1}{c|}{ Cost/m } & Cost/kA-m* & Cost/m & \multicolumn{1}{c|}{ ost/kA-m* } \\
\hline 2 & 4.3 & $400 / 40$ & 1.71 & $4.28 / 42.80$ & 3.09 & $7.72 / 77.20$ \\
\hline 3 & 6.3 & $600 / 60$ & 1.89 & $3.15 / 31.50$ & 3.96 & $6.59 / 65.90$ \\
\hline 4 & 8.3 & $800 / 80$ & 2.07 & $2.58 / 25.80$ & 4.82 & $6.03 / 60.30$ \\
\hline 5 & 10.2 & $1,000 / 100$ & 2.25 & $2.25 / 22.50$ & 5.69 & $5.69 / 59.60$ \\
\hline 6 & 11.9 & $1,200 / 120$ & 2.42 & $2.02 / 20.20$ & 6.56 & $5.47 / 54.70$ \\
\hline 7 & 13.7 & $1,400 / 140$ & 2.60 & $1.86 / 18.60$ & 7.43 & $5.31 / 53.10$ \\
\hline 8 & 15.3 & $1,600 / 160$ & 2.78 & $1.74 / 17.40$ & 8.30 & $5.19 / 51.90$ \\
\hline 9 & 17.2 & $1,800 / 180$ & 2.96 & $1.64 / 16.40$ & 9.17 & $5.09 / 50.90$ \\
\hline 10 & 19.2 & $2,000 / 200$ & 3.14 & $1.57 / 15.70$ & 10.03 & $5.02 / 50.20$ \\
\hline
\end{tabular}

*The first number is for $\mathrm{J}_{\mathrm{c}}=10^{6} \mathrm{a} / \mathrm{cm}^{2}$, the second for $\mathrm{J}_{\mathrm{c}}=10^{5} \mathrm{a} / \mathrm{cm}^{2}$ 


\subsection{Sensitivity to Operating Temperature}

The roadmap and its objectives were stated in terms of performance of the wires at liquid nitrogen temperatures, $77 \mathrm{~K}$ at sea level. A relevant issue may be how the wire cost stated in terms of $\$ / \mathrm{kA}-\mathrm{m}$ varies with operating temperature. For some applications, operations with a cryocooler at temperatures lower than $77 \mathrm{~K}$ may be feasible. The cost of manufacture of the wire will be the same, of course, but the performance will be enhanced at lower temperature. This will increase the cost of operation of the system, but decrease the cost for wire at the same current load.

The variation in $\mathrm{J}_{\mathrm{c}}$ as a function of operating temperature has been reported in many references. Figure 1.5 in Ref. 11 is chosen to represent this variation. The original source for this figure is unknown, but is believed to be a consensus of measurements from several of the national laboratories.

For the base case conductor that meets the goals of $10^{6} \mathrm{amps} / \mathrm{cm}^{2}$ at no field and $10^{5}$ amps $/ \mathrm{cm}^{2}$ in 5 Tesla flux density parallel to the c-axis at $77 \mathrm{~K}$, the critical current density resulting from applying the temperature correction and resulting cost in $\$ / \mathrm{kA}-\mathrm{m}$ for the electron beam case are shown in Table 6.9-1. Extrapolations to $40 \mathrm{~K}$ and lower are based on extending the data from the reference on a straight line basis.

The results indicate that it may well be more economical for some applications such as motors, generators, magnets and possibly transformers to operate at a temperature lower than the liquid nitrogen boiling temperature in order to minimize overall system life cycle costs.

\subsection{Cost Sensitivity to Laser Energy Target Removal Efficiency}

As previously noted in Section 2.3, there is uncertainty in the amount of laser energy required to dislodge a unit mass of YBCO target material in the PLD process. A base case value of $3.4 \times 10^{-5}$ grams/Joule was assumed, based upon being 3 times the experimental value reported by Venkatesan, 1988. Since this assumption is critically important to the economics of the PLD process, a sensitivity analysis of the effect of the parameter is in order. Recall that the total mass flow rate liberated from the target(s) needs to be 1,956 grams/hour, at $200 \mathrm{pulses} / \mathrm{sec}$, each pulse being 1 Joule, the number of lasers required for various target removal efficiencies is listed in Table 6.10-1, along with estimated cost. 
Table 6.8-1 Wire Manufacturing Cost Versus Operating Temperature

\begin{tabular}{|c|c|c|c|c|}
\hline & \multicolumn{2}{|c|}{$\mathrm{B}=0$} & \multicolumn{2}{c|}{$\mathrm{B}=5 \mathrm{~T}, \perp \mathrm{c}-$ axis } \\
\hline $\mathrm{T}(\mathrm{K})$ & $\mathrm{J}_{\mathrm{c}}\left(\mathrm{a} / \mathrm{cm}^{2}\right)$ & $\$ / \mathrm{kA}-\mathrm{m}$ & $\mathrm{J}_{\mathrm{c}}\left(\mathrm{a} / \mathrm{cm}^{2}\right)$ & $\$ / \mathrm{kA}-\mathrm{m}$ \\
\hline 77 & $10^{6}$ & 4.28 & $10^{5}$ & 42.80 \\
\hline 70 & $1.64 \times 10^{6}$ & 2.61 & $2.0 \times 10^{5}$ & 21.40 \\
\hline 60 & $2.55 \times 10^{6}$ & 1.68 & $4.39 \times 10^{5}$ & 9.75 \\
\hline 50 & $3.45 \times 10^{6}$ & 1.24 & $7.99 \times 10^{5}$ & 5.36 \\
\hline 40 & $4.36 \times 10^{6}$ & 0.98 & $1.36 \times 10^{6}$ & 3.15 \\
\hline 30 & $5.27 \times 10^{6}$ & 0.81 & $1.88 \times 10^{6}$ & 2.28 \\
\hline 20 & $6.18 \times 10^{6}$ & 0.69 & $2.4 \times 10^{6}$ & 1.78 \\
\hline 10 & $7.09 \times 10^{6}$ & 0.60 & $3.0 \times 10^{6}$ & 1.93 \\
\hline 4.2 & $7.62 \times 10^{6}$ & 0.56 & $3.3 \times 10^{6}$ & 1.30 \\
\hline
\end{tabular}

Table 6.9-1 Cost Sensitivity to Laser Target Removal Efficiency

\begin{tabular}{|c|c|c|c|c|}
\hline $\begin{array}{c}\text { Efficiency } \\
\text { Gms/hr/Laser }\end{array}$ & $\begin{array}{c}\text { Number Lasers } \\
\text { Required }\end{array}$ & $\begin{array}{c}\text { Number Vacuum } \\
\text { Chambers Req. }\end{array}$ & Cost, $\$ / m$ & Cost, $\$ / k A-m^{*}$ \\
\hline 8.16 & 240 & 24 & 5.58 & $13.95 / 139.50$ \\
\hline 16.32 & 120 & 12 & 4.33 & $10.83 / 108.30$ \\
\hline 24.48 & 80 & 8 & 3.09 & $7.72 / 77.20$ \\
\hline 32.6 & 60 & 6 & 2.78 & $6.94 / 69.40$ \\
\hline 48.9 & 40 & 4 & 2.46 & $6.16 / 61.60$ \\
\hline 97.8 & 20 & 2 & 2.15 & $5.38 / 53.80$ \\
\hline
\end{tabular}

*First number is for $\mathrm{J}_{\mathrm{c}}=10^{6} \mathrm{a} / \mathrm{cm}^{2}$, second for $\mathrm{J}_{\mathrm{c}}=10^{5} \mathrm{a} / \mathrm{cm}^{2}$

\subsection{Conclusions}

The results of this study establish a framework for evaluation of the cost impact of many performance parameters in coated conductor manufacturing systems. Since the cost and concepts are based on early developmental results and engineering judgement, the study should be updated periodically based on latest data to enhance its usefulness. The study should be expanded to include other promising processes under consideration or development for manufacture of coated conductors. Review of this study by as wide a group of experts from industry, national laboratories and universities as possible is desirable to facilitate improving accuracy of the estimates and communication on the issues involved.

The results for the case of achieving the $\$ 10 / \mathrm{kA}-\mathrm{m}$ goal at a $\mathrm{J}_{\mathrm{c}}$ of $10^{5} \mathrm{a} / \mathrm{cm}^{2}$ applicable to applications requiring a magnetic field perpendicular to the direction of current flow may be viewed as somewhat discouraging. However, there is ample margin for improvement due to continued development and engineering that could enable meeting the goal of $\$ 10 / \mathrm{kA}-\mathrm{m}$. 


\section{References}

1. Wu, X. D., et al, "Properties of $\mathrm{YBa}_{2} \mathrm{Cu}_{3} \mathrm{O}_{7-\delta}$ thick film on flexible buffered metallic substrates”, Applied Physics Letters 67 (16), 16 October 1995.

2. Goyal, A., et al, "High Critical Current Density Superconducting Tapes by Epitaxial Deposition of $\mathrm{Yba}_{2} \mathrm{Cu}_{3} \mathrm{O}_{\mathrm{x}}$ Thick Films on Biaxially Textured Metals", Applied Physics Letters, 69, p. 1795, 1996.

3. Venkatesan, T. and S. M. Green, "Pulsed Laser Deposition: Thin Films in a Flash", The Industrial Physicist, September 1996.

4. XMR, Inc. quote for Excimer Lasers, 1997.

5. Lamda Physik, GMbH, quote and sales brochure, 1997.

6. UTSI Topical Report No. 95231-“Evaluation of Methods for Application of Epitaxial Buffer and Superconductor Layers, under review pending distribution, 1998.

7. Superconductor Week, “3M Faces Challenge in E-Beam Deposition of YBCO”, Volume 12, No. 9, May 11, 1998.

8. Hammond, Robert H., "YBCO Thick Film Manufacturing Issues: Electron Beam Evaporation Controlled by Optical Monitors", presentation at the DOE Wire Development Workshop, Tampa, Florida, Jan 31-Feb 1, 1996.

9. Hammond, Robert H., “Thick Film YBCO for Wires and Tapes: Scale-up Issues and Cost Estimates", Proceedings of the $8^{\text {th }}$ International Symposium on Superconductivity (ISS '95), published as Advances in Superconductivity VIII, Edited by M. Hayskawa and Y. Enomoto, Springer-Verlag Tokyo Publisher, 1996.

10. Hammond, Robert H., Personal Communication including detailed presentation charts from the Materials Research Society Meeting in San Francisco on April 10, 1966 and the International Conference on Metallurgical Coatings and Thin Films, San Diego, April 26, 1996.

11. Muehlhauser, J. W., Ed., "Research and Development Roadmap to Achieve Electrical Wire Advancements from Superconducting Coatings", Final Draft, prepared for US DOE, July 1997.

12. Kroeger, Donald M., ORNL, Review Comment During Presentation, May 5, 1998.

13. Winkleman, B. C. and T. V. Giel Jr., "Diagnostics for Real Time Control of Coated Conductor Manufacturing Processes", UTSI Topical Report, to be published. 
14. Chrisey, D. B. and G. K. Hubler, Eds., "Pulsed Laser Deposition of Thin Films", John Wiley \& Sons, Inc., New York 1994.

15. Elliot, John, Fenn Manufacturing, Division of United Domain Company, informal quotation on rolling mill, July 2, 1997.

16. Perry \& Chilton, Chemical Engineers Handbook, McGraw Hill Book Company, 1973.

17. Chemical Equipment Cost Index, Chemical Engineering Magazine, July 1997.

18. Michael Tomsic, Personal communication on cost of web coaters, based on previous price information from American Thin Film Company, September 19, 1997.

19. Bakish Materials Corporation, specifications and budgetary price quotations for Von Ardenne electron beam systems, April 30, 1997.

20. Means, R. S., Ed., "Square Foot Costs”, $18^{\text {th }}$ Annual Edition, 1997.

21. Venkatesan, T., et al., Applied Physics Letters, 52, pp. 1193-1195, 1988.

22. Muenchausen, R. E., et al., Applied Physics Letters, 56, pp. 578-580, 1990. 


\title{
LIFE CYCLE COST STUDY FOR COATED CONDUCTOR MANUFACTURE BY ELECTRON BEAM AND PULSED LASER DEPOSITION SYSTEMS*
}

\author{
TOPICAL REPORT
}

James N. Chapman

The University of Tennessee Space Institute

Tullahoma, Tennessee 37388-9700

June 1998

(Revised April 1999)

*This work was performed under Contract No. DE-AC22-95PC95231 


\section{DISCLAIMER}

This report was prepared as an account of work sponsored by an agency of the United States Government. Neither the United States Government nor any agency thereof, nor any of their employees, makes any warranty, express or implied, or assumes any legal liability or responsibility for the accuracy, completeness, or usefulness of any information, apparatus, product, or process disclosed, or represents that its use would not fringe privately owned rights. Reference herein to any specific commercial product, process, or service by trade name, trademark, manufacturers, or otherwise does not necessarily constitute or imply its endorsement, recommendation, or favoring by the United States Government or any agency thereof. The views and opinions of authors expressed herein do not necessarily state or reflect those of the United States Government or any agency thereof. 
Table of Contents

1.0 Introduction

2.0 Description of the Production Facility and Assumptions Used .................................. 1

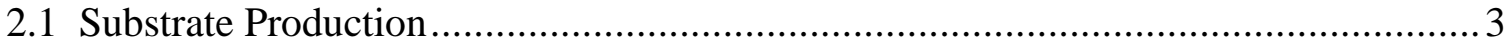

2.2 Application of YBCO Superconductor by Electron Beam Vaporization .................... 3

2.3 Application of the YBCO Superconductor by Pulsed Laser Deposition....................5

2.4 Passivation/Insulation Layer ........................................................................ 7

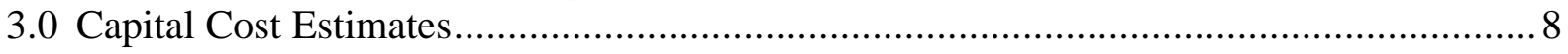

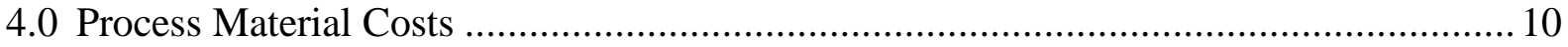

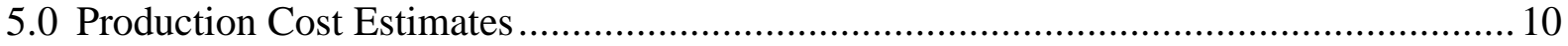

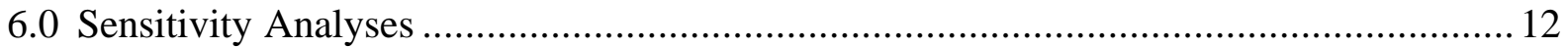

6.1 Cost Sensitivity to Deposition Rate ............................................................. 12

6.2 Cost Sensitivity to Capacity Factor .............................................................. 12

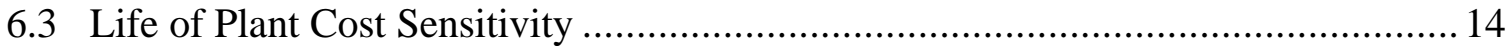

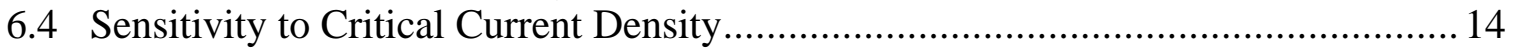

6.5 Cost Sensitivity to Material Utilization Rate ..................................................... 14

6.6 Sensitivity to Use of a Thicker Layer of Yttrium Stabilized Zirconia (YSZ).......... 16

6.7 Sensitivity to Thickness of Superconducting Layer ......................................... 16

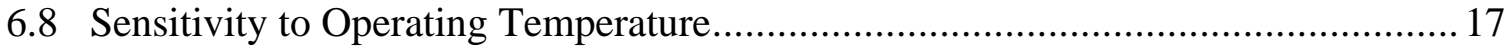

6.9 Cost Sensitivity to Laser Energy Target Removal Efficiency ............................... 17

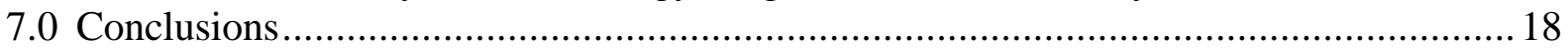

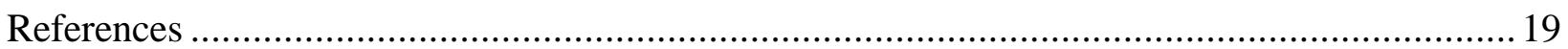




\section{List of Figures}

Figure 2.0-1 Assumed Conductor Configuration (not to scale) ........................................2

Figure 2.2-1 Concept for the Electron Beam Deposition Chamber ..................................... 4

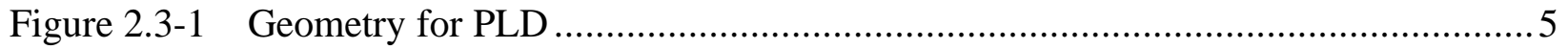

Figure 2.3-2 Pulsed Laser Deposition Concept ........................................................ 7

Figure 6.1-1 Cost Sensitivity to Deposition Rate .......................................................... 13

Figure $6.2-1$ Cost Sensitivity to Capacity Factor ........................................................... 13

Figure 6.3-1 Cost Sensitivity to Plant Lifetime ........................................................ 14

Figure 6.4-1 Cost Sensitivity to Critical Current Density ........................................... 15

Figure 6.5-1 Cost Sensitivity to Material Utilization Fraction......................................... 15 


\section{List of Tables}

Table 2-1

Table 2.2-1

Table 3.0-1

Table 3.0-2

Table 4.0-1

Table 5.0-1

Table 5.0-2

Table 5.0-3

Table 6.6-1

Table 6.7-1

Table 6.8-1

Table 6.9-1
Assumption Used in the Study

page

Ideal Deposition Power Required

Capital Cost Estimates for the Plant

Process Control System Cost Estimates

Consumable Cost for Assumed Production

Annual Capital Charge Components

Staffing Basis for the Plants Under Consideration

Production Cost Summary

Cost Impact of Requiring a 2,000 ^̊ Thick YSZ Buffer Layer

Effect of Increased Superconductor Layer Thickness

Wire Manufacturing Cost Versus Operating Temperature

Cost Sensitivity to Laser Target Removal Efficiency.

\section{2}

\section{4}




\subsection{Introduction}

Recent results from small laboratory samples have shown performance of high temperature superconductors made by epitaxial deposition in thin films to be approaching the performance needed for commercial production and application. ${ }^{1,2}$ One of the biggest hurdles to widespread application of these wires is developing a manufacturing process that will produce them in long lengths and at prices competitive to copper for applications such as motors, generators, transformers and power transmission cables.

Most of the good quality laboratory samples have been produced by Pulsed Laser Deposition (PLD) of the superconductor onto a textured substrate which has been epitaxially coated with buffer layers to provide chemical isolation and to improve the lattice match. In the PLD process for application of the YBCO layer, an excimer laser is pulsed onto a target of YBCO in a vacuum chamber which produces a beam of particulate on the sample to be coated, which is heated to a temperature favorable for formation of the desired YBCO compound. ${ }^{3}$ The laser provides a pulse of approximately 0.5 Joule on a small spot that expels the YBCO material for the pulse duration. These excimer lasers are typically limited to about 200 watts of average power and cost about $\$ 2,800$ per watt of power delivered to the target. ${ }^{4,5}$

There are several alternative processes for deposition of materials onto the substrate. UTSI has studied and compared the most commonly known processes including: PLD, electron beam, sputtering, flash evaporation, molecular beam epitaxy, electrophoresis, chemical vapor deposition, sol-gel, metal organic decomposition, electrode position and aerosol/spray pyrolysis. ${ }^{6}$ The electron beam process is being studied by at least one company, 3M, for possible utilization in a production facility. ${ }^{7}$ Also, Dr. Robert Hammond at Stanford University has studied this process. ${ }^{8,9,10}$ The e-beam seems to have advantages over the PLD process in that the cost per watt of the e-beam itself is at least 1000 times lower and the cost of raw materials is about half that of the PLD process. The latter comes from the fact that the e-beam process uses elemental Yttrium, Barium and Copper instead of the YBCO compound as in PLD. A disadvantage of the e-beam system is that it requires measurement of the concentration of $\mathrm{Y}, \mathrm{Ba}$ and $\mathrm{Cu}$ near the deposition site so that the amount being evaporated can be controlled to maintain the desired stoichiometry for formation of the correct YBCO compound. Also, the vacuum required in the deposition chamber is lower $\left(\sim 10^{-6} \mathrm{~mm} \mathrm{Hg} v s .10^{-3} \mathrm{~mm} \mathrm{Hg}\right.$ for PLD).

In this work element UTSI is tasked to evaluate promising production processes. The objective of this initial study is to compare the life cycle cost of a manufacturing facility using PLD versus a similar facility using electron beam deposition. Similar studies will be undertaken to compare these processes to other promising processes.

\subsection{Description of the Production Facility and Assumptions Used}

It is the intent of this study to compare costs in an era in which the coated conductor is fully commercial. An annual production rate of 18,000,000 meters/year was chosen as the production target. Many assumptions were chosen based on the "Research and Development Roadmap to Achieve Electrical Wire Advancements from Superconducting Coatings". ${ }^{11}$ Some 
key assumptions are listed in Table 2-1. The effects of key assumptions are evaluated by sensitivity analyses in the study.

\section{Table 2-1 Assumptions Used in the Study}

\begin{tabular}{|l|l|}
\hline Critical Current Density in the Superconductor: & $\begin{array}{l}10^{6} \mathrm{~A} / \mathrm{cm}^{2} \text { for self field, } \\
10^{5} \mathrm{a} / \mathrm{cm}^{2} \text { for } 5 \text { Tesla } \perp \text { field }\end{array}$ \\
\hline Plant Capacity: & $18,000 \mathrm{~km} / \mathrm{yr}$ \\
\hline Plant Lifetime: & 10 Years \\
\hline Wire Composition: & Shown in Figure 2-1 \\
\hline Annual Capital Charge: & $24.7 \%$, Including10\% Depreciation \\
\hline Capacity Factor: & $65 \%$ \\
\hline \multicolumn{2}{|l|}{ Deposition Rate High Enough to Permit a Single E-beam Chamber with $300 \mathrm{~kW}$ E-beams } \\
\hline
\end{tabular}
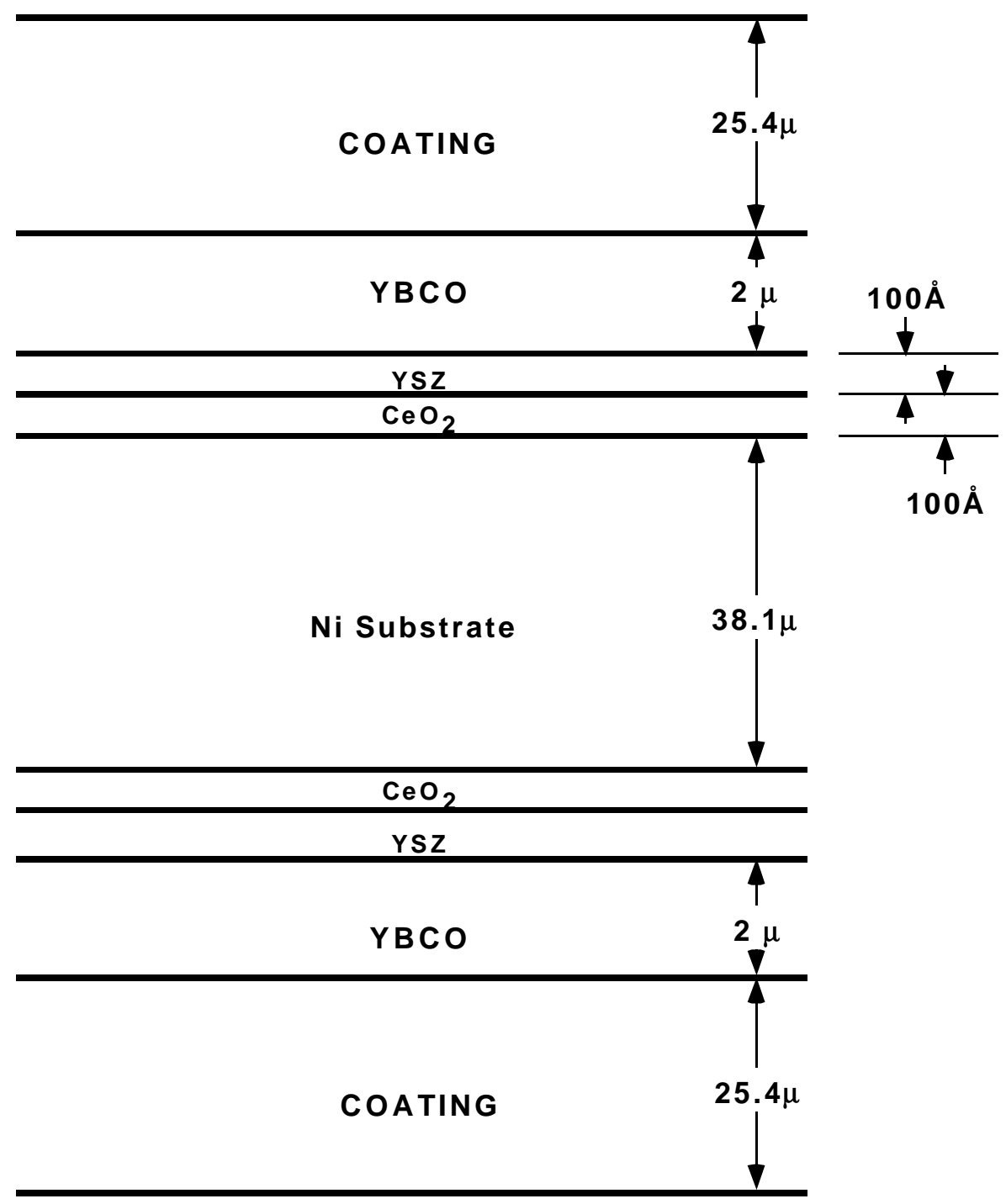

Figure 2.0-1 Assumed Conductor Configuration (Not to scale) 


\subsection{Substrate Production}

The plant choices under consideration vary only in the method of application of the YBCO superconductor layer. The initial step includes a rolling mill for high purity nickel, 10 stages, with 25\% reduction at each stage to reduce the nickel strip 95\% from its initial thickness of 762 microns ( 30 mils) to 38.1 microns $(1.5$ mils). The rolling mill includes a control system that measures the surface smoothness and thickness and implements control actions to keep the mill in tolerance. The rolled strip is stored on reels and batch annealed in an atmosphere of $96 \%$ argon and $4 \%$ hydrogen.

The textured nickel strip then is processed through two electron beam web coaters. The first applies a yttrium stabilized zirconia (YSZ) layer 100 Angstroms thick. (Note that one of the review comments was that this YSZ layer needs to be at least 2,000 Angstroms thick. ${ }^{12}$ This case is treated in a sensitivity analysis.) The second web coater applies a cerium oxide layer 100 Angstroms thick. The web coaters are near commercial products with Raman spectrometry added to evaluate the quality of the crystalline layers being deposited to assure layers adequate for epitaxial application of successive layers.

\subsection{Application of YBCO Superconductor by Electron Beam Vaporization}

The next manufacturing step is application of superconductor layers. The basic process requires heating the precursors and vaporizing them so that they are at the desired state for deposition. For the e-beam plant, multiple line beams separately vaporize yttrium, barium and copper and monotonic oxygen is provided to establish the correct oxygen stoichiometry. ${ }^{10}$ The concentration of each of the elements is measured by atomic absorption spectrometry and control applied to the electron beam to keep the concentration in tolerance. The crystalline structure is sampled by Raman spectroscopy and oxygen is controlled to achieve the desired compound. ${ }^{13}$ An assumed configuration for the electron beam chamber is shown in Figure 2.2-1. The requirements for a cooling roller and double-sided deposition force the use of two chambers or two segments in a single chamber as shown. In this configuration, the deposition area is $50 \mathrm{~cm}$ long by 30 tapes wide, each tape being $1 \mathrm{~cm}$ wide. Clearance between tapes is set at the minimal possible without mechanical interference. Assuming uniform flux of precursors in a hemisphere and a distance of the pots from the deposition surface area of $1.5 \mathrm{~m}$, the material utilization efficiency is calculated to be $10.6 \%$. The remainder condenses on the walls, shutters and other surfaces in the chamber. Following Hammond, ${ }^{10}$ monatomic oxygen is provided to facilitate the formation of optimum superconductor. The unused oxygen is expected to combine with the unused precursors in the wall deposits. What gaseous oxygen remains is pumped out by the vacuum pumps. This, and the fact that the electron beam chamber must be operated at a pressure below $10^{-6} \mathrm{~mm}$ of $\mathrm{Hg}$, increases the vacuum pump requirement for this system compared with the Pulsed Laser Deposition (PLD) system that operates at $10^{-3} \mathrm{~mm}$ of $\mathrm{Hg}$.

For the assumed production rate, a material utilization rate of $10.6 \%$ and based upon the best property data that could be found, the energy requirement for the electron beam process is 3,665 watts. This data is tabulated in Table 2.2-1. Of course, there are losses and other inefficiencies such as heat loss to the walls, heat loss to the water cooled walls of the pots and heating material that is never vaporized. Consequently, the power requirement shown should be 
considered an unattainable minimum but it does give a rough idea of the magnitude of the power needed from the electron beams.

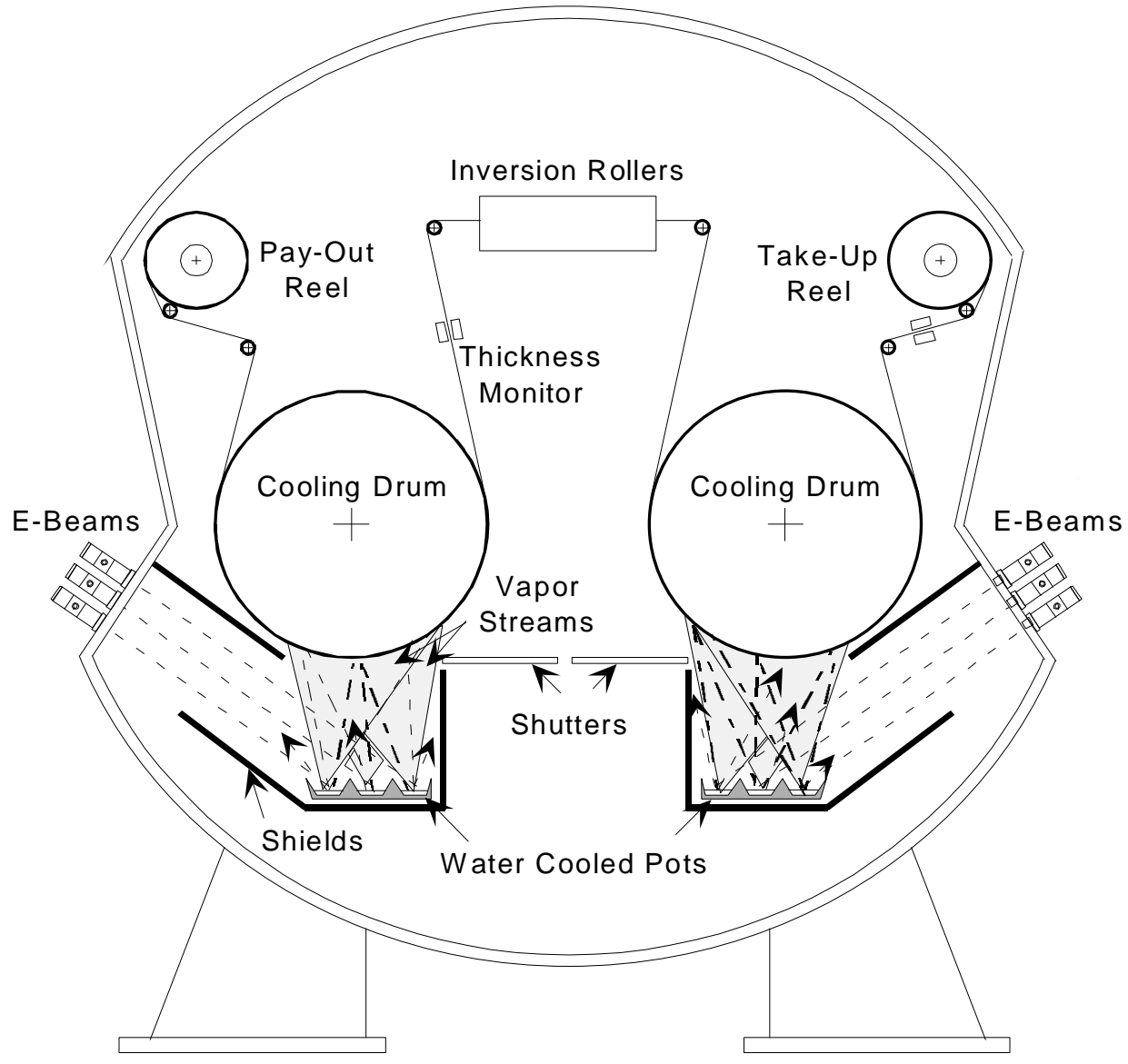

Figure 2.2-1 Concept for the Electron Beam Deposition Chamber

Table 2.2-1 Ideal Deposition Power Required

\begin{tabular}{|c|c|c|c|c|c|}
\hline $\begin{array}{c}\text { Element and } \\
\text { Vaporization } \\
\text { Temperature } \\
\text { at } 10^{-6} \text { torr }(\mathrm{K})\end{array}$ & $\begin{array}{c}\text { Mass at } \\
\text { Substrate } \\
(\mathrm{gm} / \mathrm{hr})\end{array}$ & $\begin{array}{c}\text { Mass to be } \\
\text { Vaporized } \\
(\mathrm{gm} / \mathrm{hr})\end{array}$ & $\begin{array}{c}\text { Power to } \\
\text { Vaporization } \\
\text { Temperature } \\
(\mathrm{W})\end{array}$ & $\begin{array}{c}\text { Power for } \\
\text { Vaporization (W) }\end{array}$ & $\begin{array}{c}\text { Total Power } \\
\text { Required (W) }\end{array}$ \\
\hline $\mathrm{Y}, 1246$ & 72 & 677 & 51 & 732 & 783 \\
\hline $\mathrm{Ba}, 900$ & 222 & 2,096 & 68 & 655 & 723 \\
\hline $\mathrm{Cu}, 1130$ & 154 & 1,459 & 152 & 2,007 & 2,159 \\
\hline Total & 448 & 4,232 & 271 & 3,394 & 3,665 \\
\hline
\end{tabular}

The efficiency of utilization of the electron beam power in this process is unknown. Hammond used $300 \mathrm{~kW}$ for depositing roughly one third of the amount required by this plant. ${ }^{8}$ Actual efficiencies will have to be measured experimentally. Fortunately, most commercial electron beam generators are adjustable over a wide range of beam powers. One of the major 
heat losses is to the walls of the boats from the molten precursors. The recommended boat material for barium and yttrium is tungsten. Molybdenum is recommended for copper. Both of these boat materials should be able to withstand the maximum temperature of the molten solids and reduce the beam power requirement. For this study, an assumption is made that the efficiency will be high enough to use $300 \mathrm{~kW}$ of beam power made up with six $50 \mathrm{~kW}$ beams. The efficiency is thus $3.665 \mathrm{kw} / 300 \mathrm{kw}=1.2 \%$. Since the electron beam cost is a small portion of the plant cost, the results are relatively insensitive to this assumption.

\subsection{Application of the YBCO Superconductor by Pulsed Laser Deposition}

Pulsed laser deposition concentrates a small amount of energy (typically less than a Joule) onto a very small spot of the target over a short period. The incident laser energy initially vaporizes a thin layer of the target and subsequently produces a pulse of particulate that has stoichiometry representative of the target within a reasonable beam width. The vaporized material has been found to not be stoichiometric as the target material, but the solid particulate flux is stoichiometric within reasonable limits of applied power density. The geometry method is shown in Figure 2.3-1. Venkatesan ${ }^{21}$ has shown that the particle flux is stoichiometric for $\theta= \pm 20^{\circ}$ in applying YBCO. This value is used in the subsequent calculations as the limit for angular coverage, however, it is to be expected that this is also a function of the required power density used.

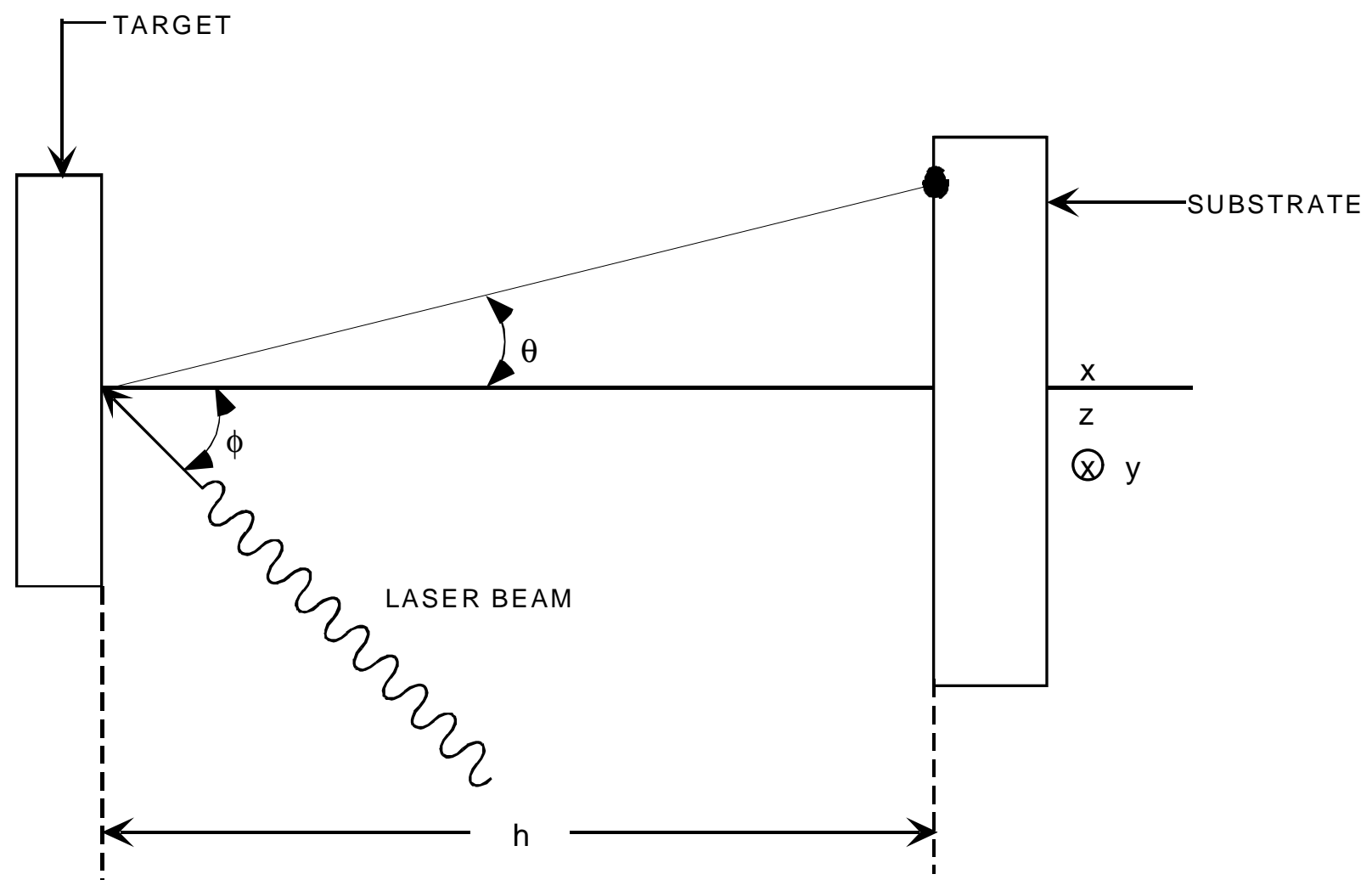

Figure 2.3-1 Geometry for PLD 
The distribution of laser energy on the substrate and the resulting particle flux on the substrate can be controlled to some extent by careful design. A rectangular pattern would seem to be most desirable for a tape in motion as the particle flux variations in the direction of travel would average out as the tape traverses the region of deposition. However, in the other direction the variation would produce films of lesser thickness. One approach to this problem might be to have the plant produce wire having a range of superconductor thickness and current carrying capacity. For this study, a vertical deposition region is used that results in $\pm 10 \%$ thickness variation. From a typical material distribution function:

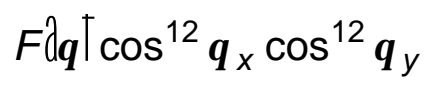

The material utilization efficiency of the material removed from the target can be expressed as:

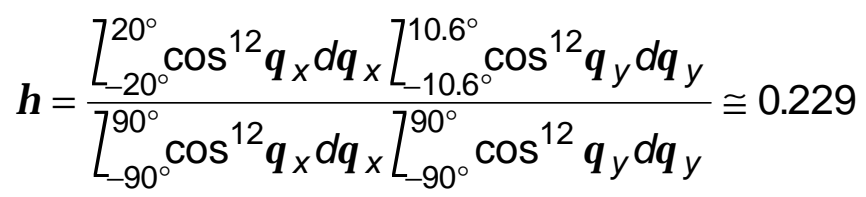

Since a good surface is needed on the target, it is not possible to utilize $100 \%$ of the YBCO in the pot. Utilization of $70 \%$ has been suggested as a goal. If this is assumed, the overall material utilization efficiency becomes: $(.229)(.7)=.16$.

The next issue that must be addressed is the energy efficiency of the laser beam. The total mass of YBCO to be deposited at the substrate is 448 grams/hour. Using the $22.9 \%$ efficiency calculated above for target to substrate transfer, $448 \mathrm{gms} / \mathrm{hr} / .229=1,956 \mathrm{gms} / \mathrm{hr}$ must be dislodged from the target into the beam. The question of how much incident power is required to dislodge this amount of YBCO is difficult if for no other reason than the effect of producing the particulate flux is unknown. Data from laboratory experiments give generally unfavorable indications. For example, Venkatesan $1988^{21,14}$ shows $1.14 \times 10^{-5}$ grams/Joule of energy and Munchausen ${ }^{22,14} 1990$ shows $3.75 \times 10^{-6}$ grams/Joule (using the average incident energy of $3.5 \mathrm{Joules} / \mathrm{cm}^{2}$ ). If one chooses an excimer laser having $200 \mathrm{pulses} / \mathrm{sec}$ of 1 Joule/pulse, the number of lasers required would be 240 and 725, respectively. This is a key issue as this number of lasers with their accompanying vacuum chambers and instrumentation would almost certainly not be economical in a large scale production facility. Based on engineering the system for production, rather than experiment, the base case is chosen at 3 times the rate of Venkatesan 1988, or $3.4 \times 10^{-5}$ grams/Joule. This implies 80 lasers, operating at 200 pulses/sec with energy level of 1 Joule/pulse.

It does not appear feasible to have a single chamber with 80 lasers radiating the YBCO target. The limit of practicality seems to be about five laser ports. However, with this level of power (a maximum of 1,000 watts) this substrate will likely need heating to get the optimum deposition temperature rather than cooling as in the electron beam case. This opens up the feasibility of simultaneous, double-sided coating. Surface temperature heating would be by radiant lamps. With this concept, 5 lasers could be arranged on each side of a vertically positioned substrate (See Figure 2.3-1). The production rate would then require eight chambers in parallel. Figure 2.3-2 shows the concept used for cost calculation. 


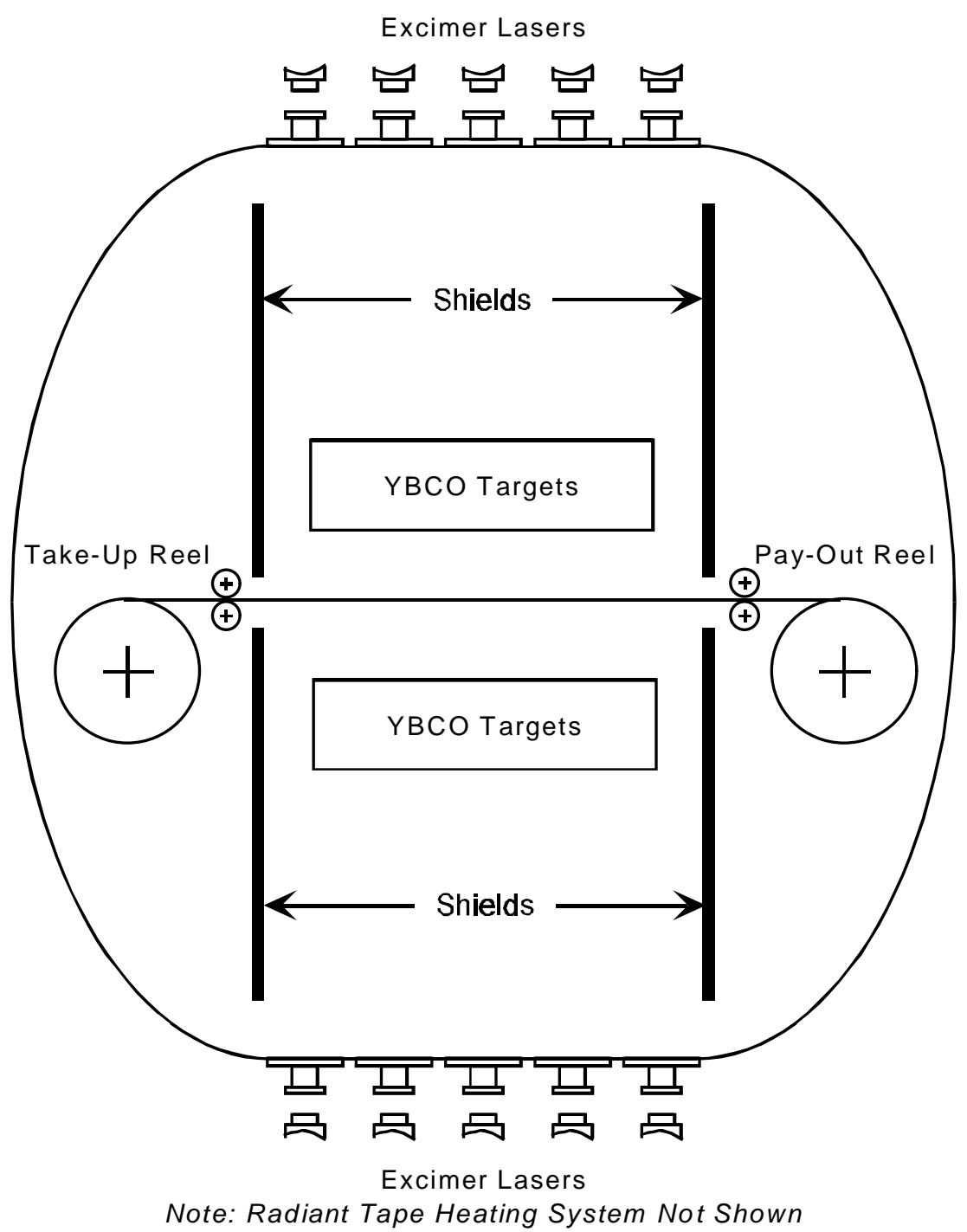

Figure 2.3-2 Pulsed Laser Deposition Concept

\subsection{Passivation/Insulation Layer}

It is necessary to provide a layer to protect the superconductor tape from the influences of the environment in which it will be used and to provide electrical insulation from ground or other potentials. Very little work has been done on optimizing this layer for thin film superconductors. It is likely that the optimum layer to meet the requirement will depend upon the application for the superconductor. For this study, it has been assumed that the wire is insulated in a manner similar to current copper magnet wire. The capital costs include equipment to dip and dry, patterned after enamel application to copper wires used for motor windings. The material cost is considered negligible. As this requirement is developed in more detail, costs may need to be added to perform this function. 
The estimate of capital cost for the plants described are tabulated in Table 3.0-1. In this section, the source and logic for these cost estimates are discussed.

The rolling mill estimate was obtained from a manufacturer ${ }^{15}$ and provides for a ten stage mill that will reduce $25 \%$ at each stage or $95 \%$ overall. The estimate is for operation in air. The mill can be provided to work in inert gas if required, but at additional cost. The annealing furnace cost estimate was derived from a chemical engineering handbook ${ }^{16}$ and adjusted for price inflation $^{17}$ and capacity. It is to be capable of operating in a mixture of $96 \%$ inert gas with $4 \%$ hydrogen. The capacity is $600 \mathrm{~km}$ per charge. The estimate for two electron beam web coaters to apply the $\mathrm{YSZ}$ and $\mathrm{CeO}_{2}$ buffer layers was based on data from the American Thin Film Company. ${ }^{18}$

Table 3.0-1 Capital Cost Estimates for the Plant

\begin{tabular}{|l|r|r|}
\hline \multicolumn{1}{|c|}{ Cost Category } & Electron Beam $(\$)$ & \multicolumn{1}{|c|}{ PLD (\$) } \\
\hline Rolling Mill & 150,000 & 150,000 \\
\hline Heat Treatment Facility & 443,000 & 443,000 \\
\hline E-Beam Web Coater & $4,000,000$ & $4,000,000$ \\
\hline E-Beam-YBCO & $1,419,000$ & 0 \\
\hline PLD-YBCO & 0 & $41,500,000$ \\
\hline Vacuum Chamber for YBCO & $1,382,616$ & $5,330,600$ \\
\hline Monatomic Oxygen System & 402,000 & 0 \\
\hline Oxygen Monitor & 52,000 & 0 \\
\hline Environmental Treatment & 100,000 & 100,000 \\
\hline Passivation/Insulation & $1,000,000$ & $1,000,000$ \\
\hline Tape Handling System & 500,000 & 500,000 \\
\hline Control Systems & $6,209,000$ & $4,109,000$ \\
\hline Laboratory/.QA Test Facility & $1,500,000$ & $1,500,000$ \\
\hline Site \& Development & 550,000 & 550,000 \\
\hline Electrical Substations & $1,000,000$ & $1,000,000$ \\
\hline Buildings & $3,720,000$ & $3,720,000$ \\
\hline Sub Total & $22,427,616$ & $63,902,600$ \\
\hline AE Fee @ 15\% & $3,364,142$ & $9,585,390$ \\
\hline & & \\
\hline Sub Total & $25,791,758$ & $73,487,990$ \\
\hline Contingency @ 20\%, \$ & $5,158,352$ & $14,697,598$ \\
\hline & & $88,185,588$ \\
\hline Total Capital Cost, \$ & $30,950,110$ & \\
\hline
\end{tabular}

The vacuum chamber cost for electron beam deposition was derived from the Kurt J. Lesker Company Vacuum Products Catalog and scaled to $60 \mathrm{~cm}$ diameter. It was then doubled for two-sided application. The cost includes six $50 \mathrm{~kW}$ electron beams at a quoted price of $\$ 1.20 /$ watt of beam power. ${ }^{19}$ The monatomic oxygen system and oxygen monitor costs are taken from Hammond ${ }^{8}$ and scaled as required. 
As previously noted, 80 excimer lasers power the PLD deposition system. The cost is based on a quoted price from the manufacturer. The vacuum chamber for PLD needs to be 60 $\mathrm{cm}$ in diameter but the tape can be mounted vertically for simultaneous application of both sides on the same pass. The higher operating pressure and the absence of an auxiliary oxygen supply simplify the chamber compared with the electron beam case. The source of basic cost data is the same as for the electron beam chamber.

The environmental control system for plants using either of these processes should be very simple. Most of the unused precursors will condense on the walls and shields in the chambers and will need to be cleaned off periodically. Any remaining particulate will be filtered out before entering the vacuum pumps. No disposal costs for the solid precursor have been included because it is anticipated that the material will be marketable for recycling. The only known gaseous pollutant is the hydrogen used in annealing the metal substrate. The cost reflects a small, gas assisted flare stack to which all the gases pumped from chambers and the annealing furnaces would be routed.

The passivation/insulation system is largely undetermined. The capital cost included represents a rough engineering estimate of the cost of a 'dip and dry' system similar to that used on copper magnet wire. The tape handling system is likewise not a refined cost estimate but a rough estimate. Handling this thin tape reliably is an important issue for the success of the plant.

The process control system costs are a combination of engineering estimates and values derived from references. Table 3.0-2 lists the components of this estimate.

Table 3.0-2 Process Control System Cost Estimates

\begin{tabular}{|l|r|r|}
\hline \multicolumn{1}{|c|}{ Control Sought } & \multicolumn{1}{c|}{$\begin{array}{c}\text { Electron Beam } \\
\text { Plant }\end{array}$} & \multicolumn{1}{c|}{ PLD Plant } \\
\hline Rolling and Annealing & 59,300 & 59,300 \\
\hline Crystal Quality, $\mathrm{O}_{2}$ Content & 200,000 & 200,000 \\
\hline Surface Smoothness & 50,000 & 50,000 \\
\hline Stoichiometry in E-Beam System & $2,100,000$ & $3,600,000$ \\
\hline Overall Process Control & $3,600,000$ & \\
\hline & & $4,109,300$ \\
\hline Total Process Control & $6,209,000$ & \\
\hline
\end{tabular}

The laboratory and quality assurance costs include general-purpose laboratory equipment including $\mathrm{x}$-ray diffraction, scanning electron microscope, superconductivity test set and atomic force microscopy equipment. The major QA expense is for a capability to final test a reel of cable at liquid nitrogen temperature for critical current.

The site is 10 acres of land with driveways, parking areas and lighting. The metal building is sized at $100,000 \mathrm{ft}^{2}$ and estimated ${ }^{20}$ at $\$ 37.20 / \mathrm{ft}^{2}$. The size of the substation, $25 \mathrm{MWe}$ and the costs are engineering estimates. 
The architect-engineer fee is estimated at $15 \%$ of the total plant and equipment cost. It is anticipated that this will involve an architect for the building and grounds and a specialized engineering firm for the production process equipment.

Finally, a contingency of $20 \%$ is included. It is anticipated that this will be a real cost and the amount is not believed to be excessive, even assuming that this technology is fully developed. In fact, a review comment was received that it might be appropriate to include a process contingency in addition to the plant contingency. However, since this study assumes that the technology has been developed and proven, no process contingency was included.

\subsection{Process Material Costs}

The estimated costs for consumables for both processes are listed in Table 4.0-1. The prices used are derived from estimates by current suppliers for quantities required for this plant. A material utilization efficiency of $10.6 \%$ is assumed for the electron beam process and $16 \%$ for the PLD Process.

Table 4.0-1 Consumable Cost for Assumed Production

\begin{tabular}{|l|r|r|r|}
\hline \multicolumn{2}{|c|}{} & \multicolumn{1}{c|}{ E-Beam } & \multicolumn{1}{c|}{ PLD } \\
\hline Materials Cost & Unit Cost $(\$)$ & Annual Cost $(\$)$ & Annual Cost (\$) \\
\hline Yttrium & $38.27 / \mathrm{kg}$ & $2,330,000$ & $2,330,000$ \\
\hline Barium & $345 / \mathrm{kg}$ & $2,049,000$ & \\
\hline Copper & $124 / \mathrm{kg}$ & $2,300,000$ & 79,082 \\
\hline Cerium & $41 / \mathrm{kg}$ & 523,560 & 246,865 \\
\hline YSZ & $394 / \mathrm{kg}$ & 79,082 & $8,836,425$ \\
\hline YBCO & $1,298 / \mathrm{kg}$ & 246,865 & 500,000 \\
\hline Gases, Supplies & $300 / \mathrm{kg}$ & & $11,992,372$ \\
\hline
\end{tabular}

\subsection{Production Cost Estimates}

The capital costs as shown in Table 3.0-1 result in annualized capital costs that include depreciation of the plant and equipment, interest on capital, taxes and working capital. Table 5.0-1 shows the factors used to derive the $24.7 \%$ annual cost rate for the base case of this study.

Table 5.0-1 Annual Capital Charge Components

\begin{tabular}{|l|c|}
\hline Cost of Money & $7.5 \%$ \\
\hline Income Taxes & $4.1 \%$ \\
\hline Depreciation, 10 years s/1 & $10 \%$ \\
\hline Other Taxes & $2.8 \%$ \\
\hline Working Capital & $0.2 \%$ \\
\hline
\end{tabular}


The labor costs are based on the staffing shown in Table 5.0-2 and an average labor rate of $\$ 25.00 /$ hour plus $26 \%$ for fringe benefits. The production cost summary is shown in Table 5.0-3. An annual allowance of $10 \%$ of the total capital cost is included for maintenance of plant and equipment. The materials cost is as listed in Table 4.0-1. Electricity and other utility costs are based on an engineering estimate and an overall cost of electricity of $\$ 60.00 / \mathrm{MWh}$.

Table 5.0-2 Staffing Basis for the Plants Under Consideration (units are number of employees)

\begin{tabular}{|l|c|c|}
\hline & E-BEAM & PLD \\
\hline YBCO Application & 4 & 8 \\
\hline Rolling \& Annealing Substrate & 2 & 6 \\
\hline Web Coating Buffers & 2 & 2 \\
\hline Environmental Cleanup & 2 & 2 \\
\hline Plant Maintenance & 4 & 4 \\
\hline Janitorial & 1 & 1 \\
\hline Shift Manager & 2 & 2 \\
\hline Engineer & 2 & 1 \\
\hline Receiving \& Incoming Material & 27 & 30 \\
\hline Shipping \& Materials Management & 132 & 147 \\
\hline Totals/Shift & 2 & 2 \\
\hline Total Shift Workers* & 2 & 2 \\
\hline Secretary/Accountant & 137 & 1 \\
\hline Purchasing Personnel & 2 & 2 \\
\hline Plant Manager & 2 & \\
\hline Total Labor & 2 & \\
\hline
\end{tabular}

* For Continuous Operation, Multiply by $24 X 365 / 1792=4.89$

With the annual cost of the plant and the annual production, the cost per meter of production is obtained as $\$ 1.71 / \mathrm{m}$ for the electron beam process and $\$ 3.09 / \mathrm{m}$ for the PLD process. If the goal of critical current density of $10^{6}$ amperes $/ \mathrm{cm}^{2}$ is achieved in self magnetic field, the critical current for the wire will be 400 amperes. This gives a cost per kiloamperemeter of $\$ 4.28$ and $\$ 7.72$, respectively.

At the critical current density of $10^{5}$ amperes $/ \mathrm{cm}^{2}$ which is the plan goal in a 5 Tesla magnetic field perpendicular to the direction of current flow, the critical current would be 40 amperes and the cost/ kA-m would be $\$ 42.75$ and $\$ 77.25$, respectively. 
Table 5.0-3 Production Cost Summary

\begin{tabular}{|l|r|r|}
\hline & E-Beam Process (\$) & Pulsed Laser Process(\$) \\
\hline Total Capital Cost & $30,950,110$ & $88,185,588$ \\
\hline Annual Capital Charges @ 24.7\% & $7,644,677$ & $21,781,840$ \\
\hline Maintenance @ 10\% of Capital Cost & $3,095,011$ & $8,818,559$ \\
\hline Materials Cost, \$/year & $8,028,507$ & $11,992,372$ \\
\hline Labor, \$/year & $9,013,486$ & $9,974,664$ \\
\hline Electricity, Other Utilities, \$/yr. & $3,000,000$ & $3,000,000$ \\
\hline Total Annual Cost, \$ & $30,781,681$ & $55,567,488$ \\
\hline Annual Production, Meters & $18,000,000$ & $18,000,000$ \\
\hline Critical Current Amperes* & $400 / 40$ & $400 / 40$ \\
\hline Cost, \$/Meter & 1.71 & 3.09 \\
\hline Cost, \$/Kiloampere Meter* & $4.28 / 42.75$ & $7.72 / 77.18$ \\
\hline
\end{tabular}

* First number is for $J_{c}=10^{6} \mathrm{~A} / \mathrm{cm}^{2}$, second is for $10^{5} \mathrm{~A} / \mathrm{cm}^{2}$

\subsection{Sensitivity Analyses}

The purpose of this section is to examine the sensitivity of the result to some key assumptions. For illustrative purposes these analyses use the $\mathrm{J}_{\mathrm{c}}=10^{6} \mathrm{~A} / \mathrm{cm}^{2}$ case, which is the goal for conductors in self-field. Results can be applied for other current densities by multiplying the cost by the ratio of critical current densities.

\subsection{Cost Sensitivity to Deposition Rate}

The assumption that the deposition rate is adequate for production of the rated capacity with one electron beam deposition chamber for YBCO is equivalent to a deposition rate of 1,168 $\AA / \mathrm{s}$. Although there are reports in the literature of deposition at rates up to $10,000 \AA / \mathrm{sec}$, the general evidence seems to indicate that there is a trade-off in quality (as measured by critical current density) and deposition rate. The cost sensitivity of a lower deposition rate is primarily that additional deposition chambers with related equipment would be required. That is, if only half the deposition rate can be achieved at the desired quality, two parallel deposition chambers would be required, etc. The results of this first order cost change are shown on Figure 6.1-1.

\subsection{Cost Sensitivity to Capacity Factor}

The capacity factor is defined as the annual output of the plant divided by the theoretical output if the plant operated continuously for the year at rated throughput. The cost sensitivity is calculated by letting the output vary in accordance with capacity factor. The $18,000,000 \mathrm{~m} / \mathrm{yr}$ nominal design point is at $65 \%$ capacity factor. Figure 6.2-1 plots the results for both plants. 


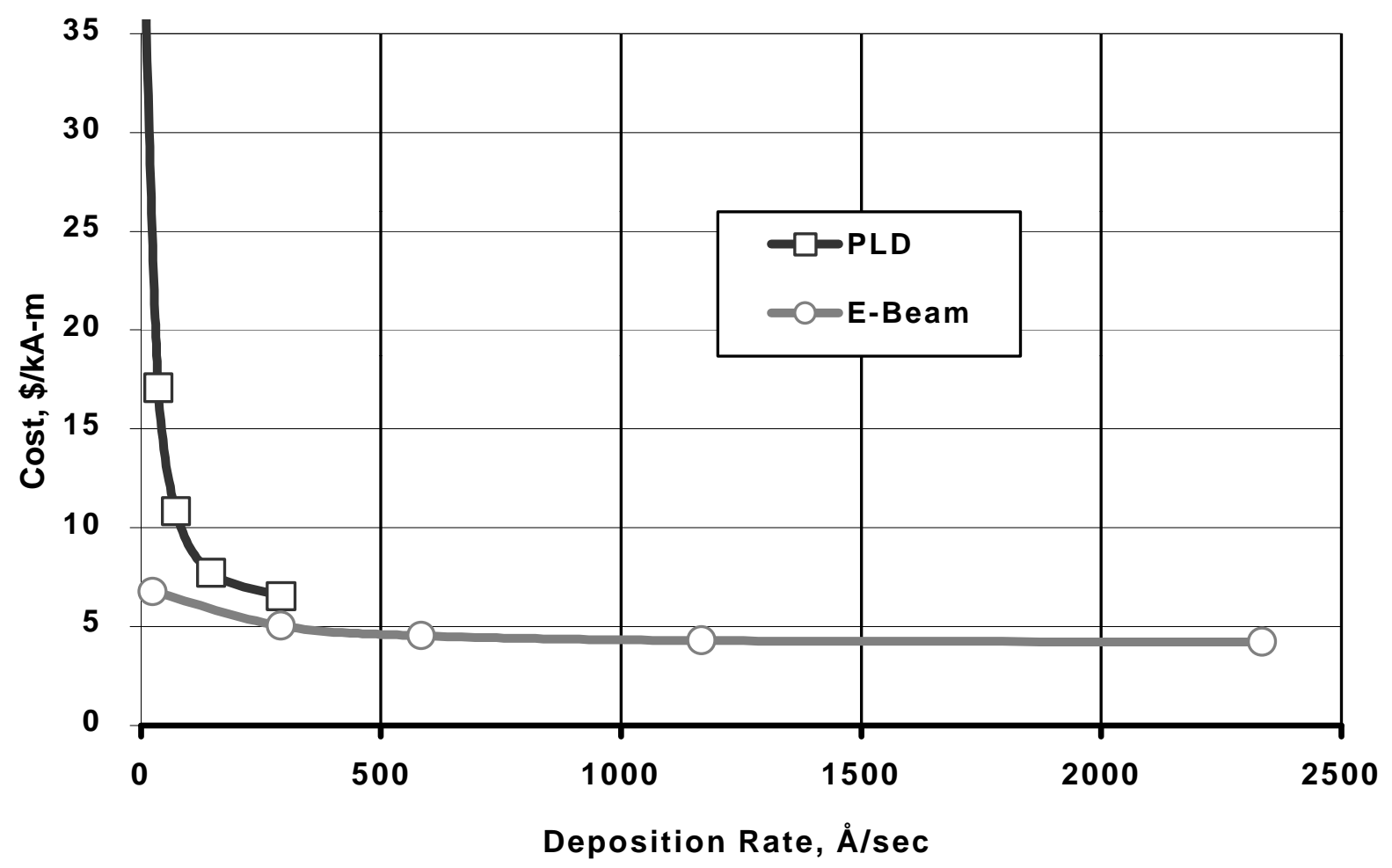

Figure 6.1-1 Cost Sensitivity to Deposition Rate

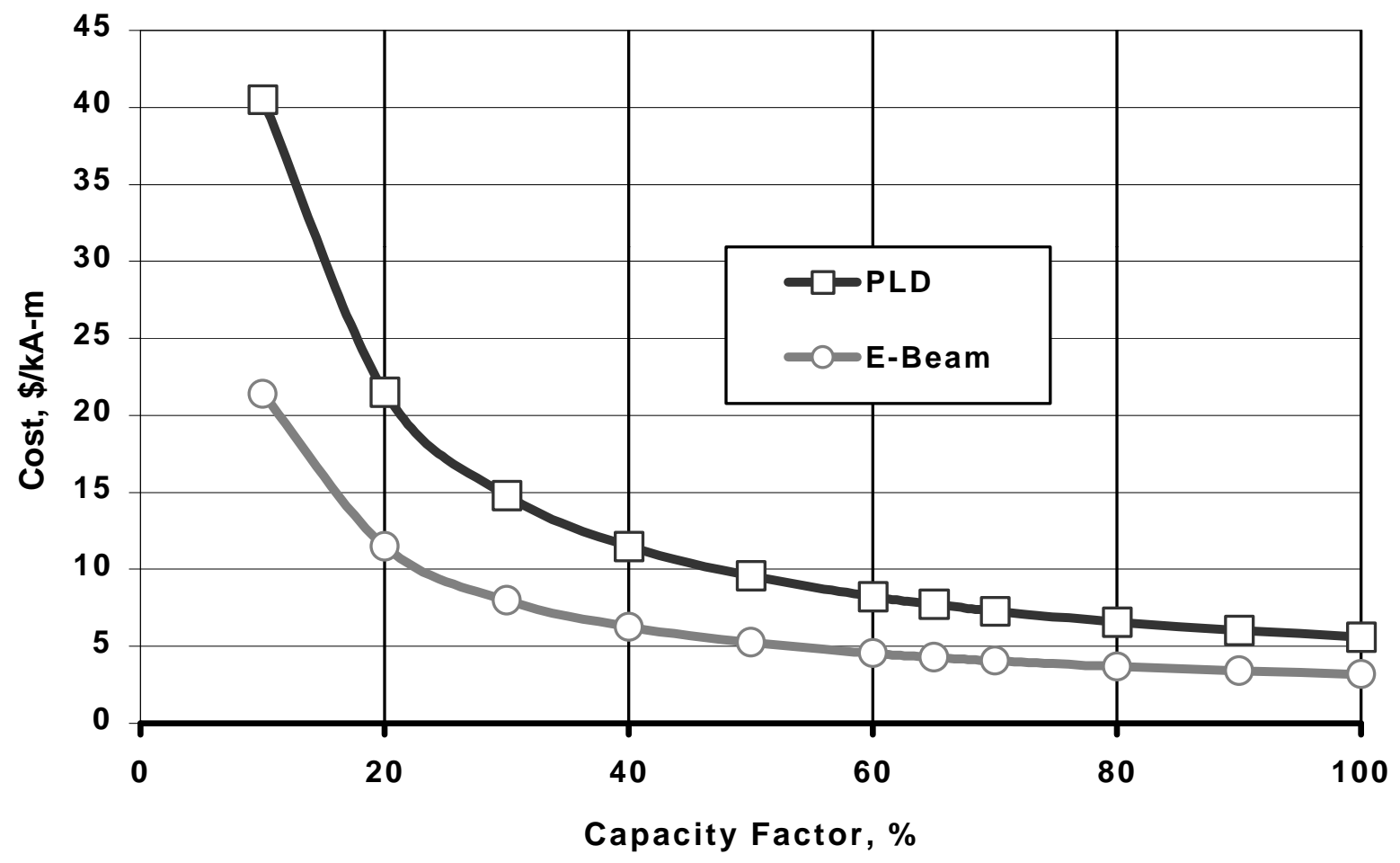

Figure 6.2-1 Cost Sensitivity to Capacity Factor 


\subsection{Life of Plant Cost Sensitivity}

The cost effect of varying plant life is in the depreciation that is a component of the annual charges for capital costs. The depreciation method used is straight line. The base case plant life of 10 years resulted in a $10 \%$ annual depreciation. The resulting cost sensitivity is shown in Figure 6.3-1.

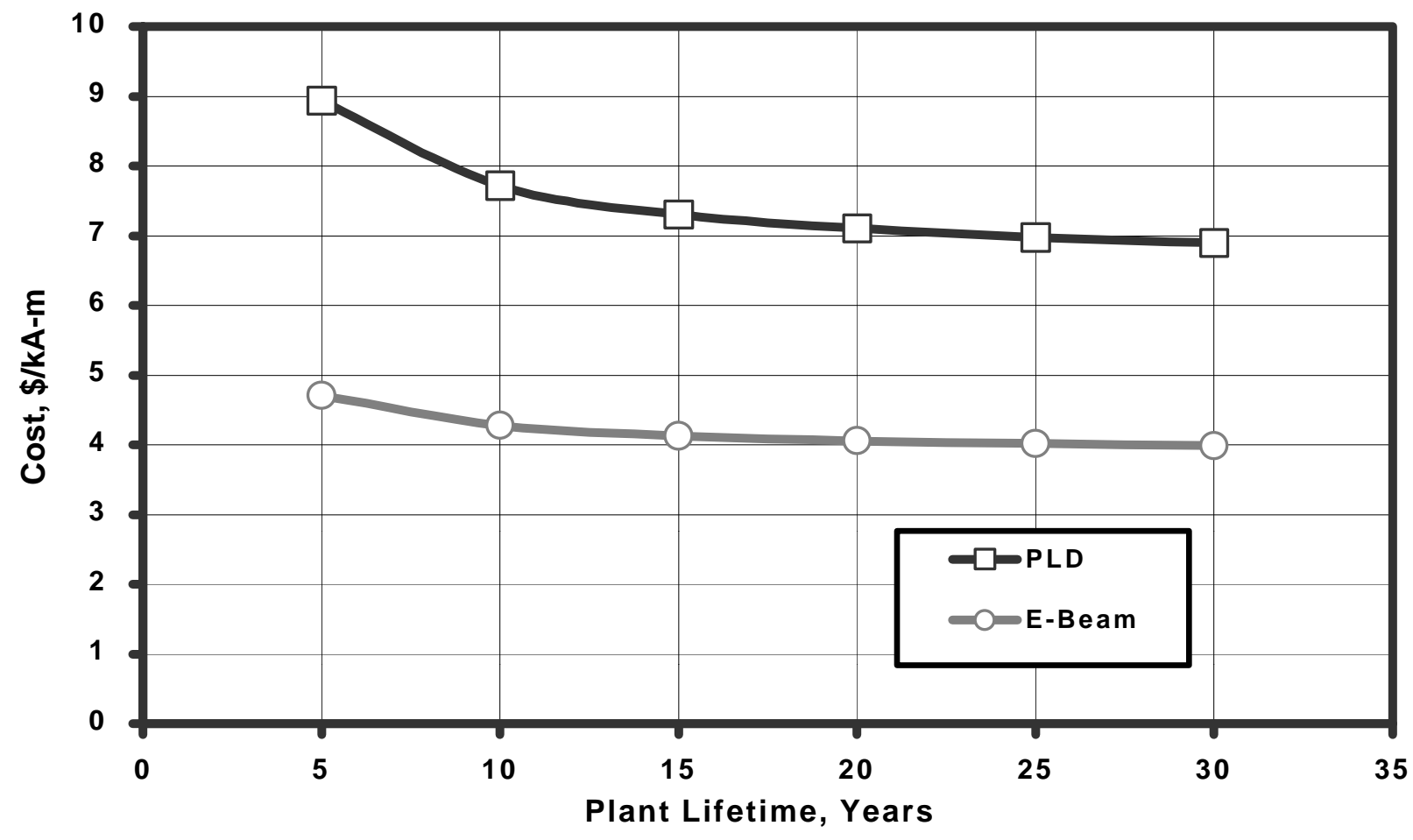

Figure 6.3-1 Cost Sensitivity to Plant Lifetime

\subsection{Sensitivity to Critical Current Density}

The critical current density achieved is an important factor because it inversely affects the number of wires required to carry a specified current and thus affects the cost per kiloampere-m. The calculated costs for a range of current densities are shown on Figure 6.4-1 on the following page.

\subsection{Cost Sensitivity to Material Utilization Rate}

The material utilization rate expresses the fraction of the purchased material that becomes part of the superconductor or buffer layer. The base case used for these calculations was $10.6 \%$ for the electron beam process and 16\% for PLD. Primary ways that this material is lost is by deposition on walls and shields in the vacuum chamber and by remaining in the pot or target after it is replaced. The cost effect of various utilization factors is shown on Figure 6.5-1, on the following page. 


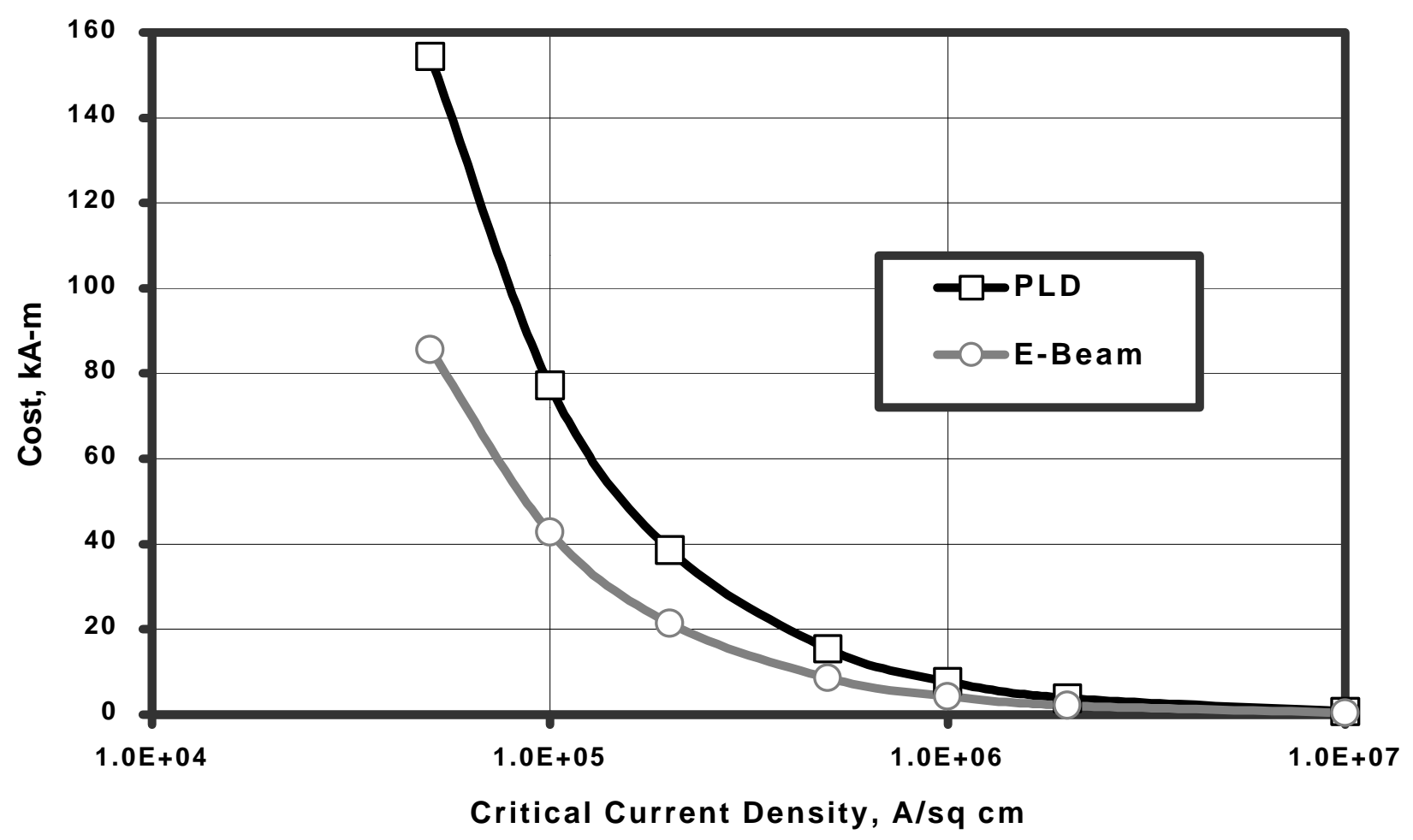

Figure 6.4-1 Cost Sensitivity to Critical Current Density

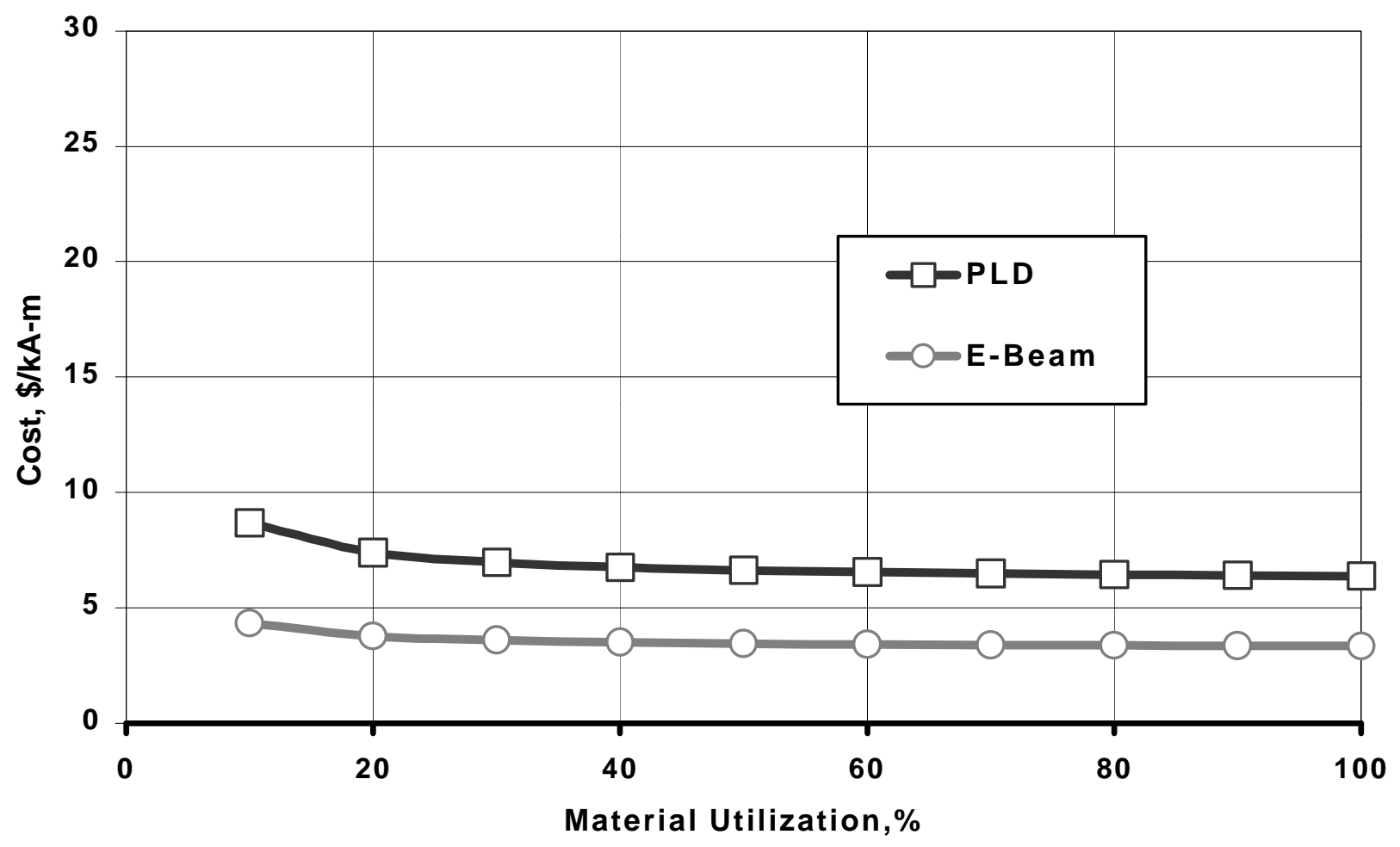

Figure 6.5-1 Cost Sensitivity to Material Utilization Fraction 


\subsection{Sensitivity to Use of a Thicker Layer of Yttrium Stabilized Zirconia (YSZ)}

One of the review comments received when this study was briefed in the early draft stage was that the YSZ layer will need to be thicker. ${ }^{12}$ It was suggested that it might need to be 2000 $\AA$ thick rather than the $100 \AA$ as used in the base case. The impact of a thicker layer on cost includes the additional material used and six additional electron beam web coaters to work in parallel in application of the YSZ buffer layer. The cost impact for a $2000 \AA$ layer is shown in Table 6.7-1.

Table 6.6-1 Cost Impact of Requiring a 2,000 ̊ Thick YSZ Buffer Layer (Base Case Cost in Parenthesis)

\begin{tabular}{|l|c|c|}
\hline & Electron Beam & PLD \\
\hline Cost $\$ / \mathrm{m}$ & $2.29(1.71)$ & $3.67(3.09)$ \\
\hline Cost $\$ / \mathrm{kA}-\mathrm{m}$ & $5.72(4.28)$ & $9.17(7.72)$ \\
\hline
\end{tabular}

\subsection{Sensitivity to Thickness of Superconducting Layer}

The base case assumed conductor shown in Figure 2.0-1 has a thickness of YBCO superconducting layer of only $2 \mu$ on each side. This is based on indications from experimental results that the crystalline structure for thicker layers deviates from that desired and the incremental critical current density declines. For the substrate, buffer and coating thickness chosen, the fill factor (defined as the ratio of superconductor to total cross section areas) is only $4.3 \%$. This is well below the $10 \%$ goal established in the plan ${ }^{11}$. It will be very difficult to meet that fill factor goal unless thicker superconductor layers can be used as the substrate and coating cannot be reduced in thickness much without compromising desired characteristics. If the technology to use thicker layers is available, improved fill factors and lower cost/kA-m can be achieved. Table 6.8-1 below illustrates the effect of using higher thicknesses of superconductor on the cost, which includes additional YBCO or YBCO precursors, plus additional YBCO application machinery. Other dimensions remain as in Figure 2.0-1.

Table 6.7-1 Effect of Increased Superconductor Layer Thickness

\begin{tabular}{|r|r|r|r|r|r|r|}
\hline \multicolumn{4}{|c|}{} & \multicolumn{2}{c|}{ E-Beam Process $(\$)$} & \multicolumn{2}{c|}{ PLD $(\$)$} \\
\hline $\mathrm{t}, \mu$ & $\mathrm{FF}(\%)$ & \multicolumn{1}{c|}{$\mathrm{I}_{\mathrm{c}}(\mathrm{a})^{*}$} & \multicolumn{1}{c|}{ Cost/m } & Cost/kA-m* & Cost/m & \multicolumn{1}{c|}{ ost/kA-m* } \\
\hline 2 & 4.3 & $400 / 40$ & 1.71 & $4.28 / 42.80$ & 3.09 & $7.72 / 77.20$ \\
\hline 3 & 6.3 & $600 / 60$ & 1.89 & $3.15 / 31.50$ & 3.96 & $6.59 / 65.90$ \\
\hline 4 & 8.3 & $800 / 80$ & 2.07 & $2.58 / 25.80$ & 4.82 & $6.03 / 60.30$ \\
\hline 5 & 10.2 & $1,000 / 100$ & 2.25 & $2.25 / 22.50$ & 5.69 & $5.69 / 59.60$ \\
\hline 6 & 11.9 & $1,200 / 120$ & 2.42 & $2.02 / 20.20$ & 6.56 & $5.47 / 54.70$ \\
\hline 7 & 13.7 & $1,400 / 140$ & 2.60 & $1.86 / 18.60$ & 7.43 & $5.31 / 53.10$ \\
\hline 8 & 15.3 & $1,600 / 160$ & 2.78 & $1.74 / 17.40$ & 8.30 & $5.19 / 51.90$ \\
\hline 9 & 17.2 & $1,800 / 180$ & 2.96 & $1.64 / 16.40$ & 9.17 & $5.09 / 50.90$ \\
\hline 10 & 19.2 & $2,000 / 200$ & 3.14 & $1.57 / 15.70$ & 10.03 & $5.02 / 50.20$ \\
\hline
\end{tabular}

*The first number is for $\mathrm{J}_{\mathrm{c}}=10^{6} \mathrm{a} / \mathrm{cm}^{2}$, the second for $\mathrm{J}_{\mathrm{c}}=10^{5} \mathrm{a} / \mathrm{cm}^{2}$ 


\subsection{Sensitivity to Operating Temperature}

The roadmap and its objectives were stated in terms of performance of the wires at liquid nitrogen temperatures, $77 \mathrm{~K}$ at sea level. A relevant issue may be how the wire cost stated in terms of $\$ / \mathrm{kA}-\mathrm{m}$ varies with operating temperature. For some applications, operations with a cryocooler at temperatures lower than $77 \mathrm{~K}$ may be feasible. The cost of manufacture of the wire will be the same, of course, but the performance will be enhanced at lower temperature. This will increase the cost of operation of the system, but decrease the cost for wire at the same current load.

The variation in $\mathrm{J}_{\mathrm{c}}$ as a function of operating temperature has been reported in many references. Figure 1.5 in Ref. 11 is chosen to represent this variation. The original source for this figure is unknown, but is believed to be a consensus of measurements from several of the national laboratories.

For the base case conductor that meets the goals of $10^{6} \mathrm{amps} / \mathrm{cm}^{2}$ at no field and $10^{5}$ amps $/ \mathrm{cm}^{2}$ in 5 Tesla flux density parallel to the c-axis at $77 \mathrm{~K}$, the critical current density resulting from applying the temperature correction and resulting cost in $\$ / \mathrm{kA}-\mathrm{m}$ for the electron beam case are shown in Table 6.9-1. Extrapolations to $40 \mathrm{~K}$ and lower are based on extending the data from the reference on a straight line basis.

The results indicate that it may well be more economical for some applications such as motors, generators, magnets and possibly transformers to operate at a temperature lower than the liquid nitrogen boiling temperature in order to minimize overall system life cycle costs.

\subsection{Cost Sensitivity to Laser Energy Target Removal Efficiency}

As previously noted in Section 2.3, there is uncertainty in the amount of laser energy required to dislodge a unit mass of YBCO target material in the PLD process. A base case value of $3.4 \times 10^{-5}$ grams/Joule was assumed, based upon being 3 times the experimental value reported by Venkatesan, 1988. Since this assumption is critically important to the economics of the PLD process, a sensitivity analysis of the effect of the parameter is in order. Recall that the total mass flow rate liberated from the target(s) needs to be 1,956 grams/hour, at $200 \mathrm{pulses} / \mathrm{sec}$, each pulse being 1 Joule, the number of lasers required for various target removal efficiencies is listed in Table 6.10-1, along with estimated cost. 
Table 6.8-1 Wire Manufacturing Cost Versus Operating Temperature

\begin{tabular}{|c|c|c|c|c|}
\hline & \multicolumn{2}{|c|}{$\mathrm{B}=0$} & \multicolumn{2}{c|}{$\mathrm{B}=5 \mathrm{~T}, \perp \mathrm{c}-$ axis } \\
\hline $\mathrm{T}(\mathrm{K})$ & $\mathrm{J}_{\mathrm{c}}\left(\mathrm{a} / \mathrm{cm}^{2}\right)$ & $\$ / \mathrm{kA}-\mathrm{m}$ & $\mathrm{J}_{\mathrm{c}}\left(\mathrm{a} / \mathrm{cm}^{2}\right)$ & $\$ / \mathrm{kA}-\mathrm{m}$ \\
\hline 77 & $10^{6}$ & 4.28 & $10^{5}$ & 42.80 \\
\hline 70 & $1.64 \times 10^{6}$ & 2.61 & $2.0 \times 10^{5}$ & 21.40 \\
\hline 60 & $2.55 \times 10^{6}$ & 1.68 & $4.39 \times 10^{5}$ & 9.75 \\
\hline 50 & $3.45 \times 10^{6}$ & 1.24 & $7.99 \times 10^{5}$ & 5.36 \\
\hline 40 & $4.36 \times 10^{6}$ & 0.98 & $1.36 \times 10^{6}$ & 3.15 \\
\hline 30 & $5.27 \times 10^{6}$ & 0.81 & $1.88 \times 10^{6}$ & 2.28 \\
\hline 20 & $6.18 \times 10^{6}$ & 0.69 & $2.4 \times 10^{6}$ & 1.78 \\
\hline 10 & $7.09 \times 10^{6}$ & 0.60 & $3.0 \times 10^{6}$ & 1.93 \\
\hline 4.2 & $7.62 \times 10^{6}$ & 0.56 & $3.3 \times 10^{6}$ & 1.30 \\
\hline
\end{tabular}

Table 6.9-1 Cost Sensitivity to Laser Target Removal Efficiency

\begin{tabular}{|c|c|c|c|c|}
\hline $\begin{array}{c}\text { Efficiency } \\
\text { Gms/hr/Laser }\end{array}$ & $\begin{array}{c}\text { Number Lasers } \\
\text { Required }\end{array}$ & $\begin{array}{c}\text { Number Vacuum } \\
\text { Chambers Req. }\end{array}$ & Cost, $\$ / m$ & Cost, $\$ / k A-m^{*}$ \\
\hline 8.16 & 240 & 24 & 5.58 & $13.95 / 139.50$ \\
\hline 16.32 & 120 & 12 & 4.33 & $10.83 / 108.30$ \\
\hline 24.48 & 80 & 8 & 3.09 & $7.72 / 77.20$ \\
\hline 32.6 & 60 & 6 & 2.78 & $6.94 / 69.40$ \\
\hline 48.9 & 40 & 4 & 2.46 & $6.16 / 61.60$ \\
\hline 97.8 & 20 & 2 & 2.15 & $5.38 / 53.80$ \\
\hline
\end{tabular}

*First number is for $\mathrm{J}_{\mathrm{c}}=10^{6} \mathrm{a} / \mathrm{cm}^{2}$, second for $\mathrm{J}_{\mathrm{c}}=10^{5} \mathrm{a} / \mathrm{cm}^{2}$

\subsection{Conclusions}

The results of this study establish a framework for evaluation of the cost impact of many performance parameters in coated conductor manufacturing systems. Since the cost and concepts are based on early developmental results and engineering judgement, the study should be updated periodically based on latest data to enhance its usefulness. The study should be expanded to include other promising processes under consideration or development for manufacture of coated conductors. Review of this study by as wide a group of experts from industry, national laboratories and universities as possible is desirable to facilitate improving accuracy of the estimates and communication on the issues involved.

The results for the case of achieving the $\$ 10 / \mathrm{kA}-\mathrm{m}$ goal at a $\mathrm{J}_{\mathrm{c}}$ of $10^{5} \mathrm{a} / \mathrm{cm}^{2}$ applicable to applications requiring a magnetic field perpendicular to the direction of current flow may be viewed as somewhat discouraging. However, there is ample margin for improvement due to continued development and engineering that could enable meeting the goal of $\$ 10 / \mathrm{kA}-\mathrm{m}$. 


\section{References}

1. Wu, X. D., et al, "Properties of $\mathrm{YBa}_{2} \mathrm{Cu}_{3} \mathrm{O}_{7-\delta}$ thick film on flexible buffered metallic substrates”, Applied Physics Letters 67 (16), 16 October 1995.

2. Goyal, A., et al, "High Critical Current Density Superconducting Tapes by Epitaxial Deposition of $\mathrm{Yba}_{2} \mathrm{Cu}_{3} \mathrm{O}_{\mathrm{x}}$ Thick Films on Biaxially Textured Metals", Applied Physics Letters, 69, p. 1795, 1996.

3. Venkatesan, T. and S. M. Green, "Pulsed Laser Deposition: Thin Films in a Flash", The Industrial Physicist, September 1996.

4. XMR, Inc. quote for Excimer Lasers, 1997.

5. Lamda Physik, GMbH, quote and sales brochure, 1997.

6. UTSI Topical Report No. 95231-“Evaluation of Methods for Application of Epitaxial Buffer and Superconductor Layers, under review pending distribution, 1998.

7. Superconductor Week, “3M Faces Challenge in E-Beam Deposition of YBCO”, Volume 12, No. 9, May 11, 1998.

8. Hammond, Robert H., "YBCO Thick Film Manufacturing Issues: Electron Beam Evaporation Controlled by Optical Monitors", presentation at the DOE Wire Development Workshop, Tampa, Florida, Jan 31-Feb 1, 1996.

9. Hammond, Robert H., “Thick Film YBCO for Wires and Tapes: Scale-up Issues and Cost Estimates", Proceedings of the $8^{\text {th }}$ International Symposium on Superconductivity (ISS '95), published as Advances in Superconductivity VIII, Edited by M. Hayskawa and Y. Enomoto, Springer-Verlag Tokyo Publisher, 1996.

10. Hammond, Robert H., Personal Communication including detailed presentation charts from the Materials Research Society Meeting in San Francisco on April 10, 1966 and the International Conference on Metallurgical Coatings and Thin Films, San Diego, April 26, 1996.

11. Muehlhauser, J. W., Ed., "Research and Development Roadmap to Achieve Electrical Wire Advancements from Superconducting Coatings", Final Draft, prepared for US DOE, July 1997.

12. Kroeger, Donald M., ORNL, Review Comment During Presentation, May 5, 1998.

13. Winkleman, B. C. and T. V. Giel Jr., "Diagnostics for Real Time Control of Coated Conductor Manufacturing Processes", UTSI Topical Report, to be published. 
14. Chrisey, D. B. and G. K. Hubler, Eds., "Pulsed Laser Deposition of Thin Films", John Wiley \& Sons, Inc., New York 1994.

15. Elliot, John, Fenn Manufacturing, Division of United Domain Company, informal quotation on rolling mill, July 2, 1997.

16. Perry \& Chilton, Chemical Engineers Handbook, McGraw Hill Book Company, 1973.

17. Chemical Equipment Cost Index, Chemical Engineering Magazine, July 1997.

18. Michael Tomsic, Personal communication on cost of web coaters, based on previous price information from American Thin Film Company, September 19, 1997.

19. Bakish Materials Corporation, specifications and budgetary price quotations for Von Ardenne electron beam systems, April 30, 1997.

20. Means, R. S., Ed., "Square Foot Costs”, $18^{\text {th }}$ Annual Edition, 1997.

21. Venkatesan, T., et al., Applied Physics Letters, 52, pp. 1193-1195, 1988.

22. Muenchausen, R. E., et al., Applied Physics Letters, 56, pp. 578-580, 1990. 